Romero Fernández, M. G. (2020): “Análisis de distribución potencial de Xylella fastidiosa subsp. multiplex ST-6 y Philaenus spumarius en el sur de la Península Ibérica mediante el modelo ecológico de nicho MaxEnt.", GeoFocus, $n^{\circ} 25$, p. 77-102. http://dx.doi.org/10.21138/GF.664

\title{
ANÁLISIS DE DISTRIBUCIÓN POTENCIAL DE Xylella fastidiosa subsp. multiplex ST-6 Philaenus spumarius EN EL SUR DE LA PENÍNSULA IBÉRICA MEDIANTE EL MODELO ECOLÓGICO DE NICHO MAXENT.
}

\author{
MIGUEL GUSTAVO ROMERO FERNÁNDEZ \\ Departamento Geografía Física y AGR, Facultad de Geografía, Universidad de Sevilla \\ San Fernando 4, Sevilla, España \\ romeromg@us.es
}

\section{RESUMEN}

Se ha utilizado el modelo ecológico de nicho MaxEnt para conocer la distribución potencial de Xylella fastidiosa subsp. multiplex y el vector asociado Philaenus spumarius en el sur de la Península Ibérica. La correlación de la probabilidad de presencia de la bacteria con respecto al insecto vector es del $94 \%$, ratificando la existencia de un sistema patógeno-vector. La validación interna del modelo presenta unos coeficientes AUC por encima del $90 \%$. Las validaciones externas de los errores de omisión y comisión se han realizado mediante la correlación de los valores de probabilidad obtenidos por un modelo matemático multivariable y datos no introducidos en la modelización procedentes de 914 puntos de la última infección, con una correlación de la predicción del modelo de más del $80 \%$.

Palabras clave: Xylella fastidiosa; Philaenus spumarius; MaxEnt; Modelos de Distribución de Especies.

ANALYSIS OF POTENTIAL DISTRIBUTION OF Xylella fastidiosa subsp. multiplex ST6 AND Philaenus spumarius IN THE SOUTH OF THE IBERIAN PENINSULA. THE ECOLOGICAL MODEL OF NICHE MAXENT.

\section{ABSTRACT}

The ecological model of niche MaxEnt has been used to know the potential distribution of Xylella fastidiosa subsp. multiplex and the associated vector Philaenus spumarius in the south of the Iberian Peninsula. The correlation of the probability of the presence of the bacterium with respect to the vector insect is $94 \%$, confirming the existence of a pathogenvector system. The internal validation of the model shows AUC coefficients above $90 \%$. The external validations of the omission and commission errors have been made by correlating the probability values obtained by a multivariate mathematical model and 914 independent points obtained from the last infection, which have given a correlation of the model prediction above $80 \%$. 
Romero Fernández, M. G. (2020): “Análisis de distribución potencial de Xylella fastidiosa subsp. multiplex ST-6 y Philaenus spumarius en el sur de la Península Ibérica mediante el modelo ecológico de nicho MaxEnt.", GeoFocus, $n^{\circ} 25$, p. 77-102. http://dx.doi.org/10.21138/GF.664

Keywords: Xylella fastidiosa; Philaenus spumarius; MaxEnt; Species Distribution Models.

\section{Introducción}

Xylella fastidiosa spp (Xf) es el patógeno que constituye en la actualidad la principal amenaza de numerosas especies vegetales, por lo que es considerada una bacteria de cuarentena en la Unión Europea (UE) desde el año 2000 según la Directiva 2000/29/EC (Consejo europeo 2000).

Xf es una bacteria aeróbica mesófila que se hospeda en el xilema de las plantas, siendo responsable de varias enfermedades con efectos devastadores como la "Enfermedad de Pierce" en viña, "Clorosis Variegada" en cítricos, "Decaimiento Súbito del Olivo", y el marchitamiento irreversible de numerosas especies vegetales leñosas y herbáceas.

En la década de 1940 se demostró la transmisión de la enfermedad por vectores artrópodos (Janse y Obradovic 2010), finalmente su adecuada descripción, clasificación y denominación como Xf, no se produjo hasta el año 1987 según Wells et al. (1987). En 2013 se descubrió que la bacteria había migrado del continente americano de donde es autóctona, al europeo por transporte de material vegetal infectado, cuando la enfermedad del "Decaimiento Súbito del Olivo" fue identificada por primera vez en la región de Apulia, en el sureste de Italia, afectando a más 20000 has de olivos, ocasionada por Xylella. fastidiosa subsp. pauca (Saponari et al. 2013).

Desde el verano de 2014 se ha producido una dispersión espacial de la bacteria en distintos países de la UE y se han identificado nuevos hospedantes, redefiniéndose sucesivas Zonas Demarcadas (ZD), esta son áreas establecidas por la administración acorde a una distancia de seguridad respecto a los focos detectados, en la que se adoptan medidas de erradicación y/o contención. Se han identificado hasta el momento tres especies de insectos considerados vectores de la bacteria: Philaenus spumarius, Neophilaenus campestris, y Philaenus italosignus.

La European Food Safety Authority (EFSA 2015) hace público el inventario de especies vegetales potencialmente susceptibles de $\mathrm{Xf}$ en condiciones naturales o experimentales, comunicando la existencia de más de 359 especies pertenecientes a 204 géneros y 75 familias botánicas. Xf podría afectar a otras especies no descritas, dificultando su impacto real por la latencia de su patología en reservorios aún desconocidos y la dificultad de su diagnóstico. No se puede excluir, que el patógeno esté presente en otras zonas geográficas no consideradas como riesgo potencial, debido a que los síntomas hayan pasado desapercibidos o confundidos con otros similares que producen tantos factores bióticos como abióticos (Janse y Obradovic 2010).

\subsection{La situación en España.}

El Ministerio de Agricultura, Pesca, Alimentación y Medio Ambiente (MAPAMA 2019), siguiendo la Directiva 2000/29/CE, Decisión UE 2015/789 del UE, ha elaborado un Plan de Contingencia basado en la prospección y toma de muestras de plantas potencialmente huéspedes y obliga a delimitar una ZD en caso de confirmación de la presencia de Xf.

El primer caso declarado en el estado español se produjo en la Comunidad Balear en el año 2015, en Mallorca, (Conselleria de Medi Ambient 2017). En la actualidad las islas de Ibiza y Menorca también están afectadas y coexisten tres subespecies de la bacteria, y diferentes Sequence Type (ST) o cepas: Xylella. fastidiosa subsp. fastidiosa.ST 1, Xylella. fastidiosa subsp. multiplex, ST-81 y ST-7 y Xylella. fastidiosa subsp. Pauca, ST-80, afectando a olivos, 


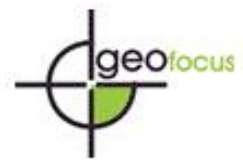

Romero Fernández, M. G. (2020): “Análisis de distribución potencial de Xylella fastidiosa subsp. multiplex ST-6 y Philaenus spumarius en el sur de la Península Ibérica mediante el modelo ecológico de nicho MaxEnt.", GeoFocus, $n^{o}$ 25, p. 77-102. http://dx.doi.org/10.21138/GF.664

almendros y otros frutales de hueso dependiendo de la cepa. Esta situación parece indicar que la presencia de la bacteria en las Islas Baleares es consecuencia de diferentes introducciones, siendo muy probable que lleve tiempo en dicho territorio y que la bacteria este ampliamente distribuida y por lo tanto, ya no se considera posible su erradicación, (Conselleria de Medi Ambient 2017).

En junio del 2017 se produce el primer foco en la Península Ibérica en Alicante, siendo el origen de los brotes detectados desconocidos (Generalitat Valenciana, Consejería de Agricultura, Medio Ambiente 2017), se trata de una única introducción. En la ZD sólo se ha detectado Xylella fastidiosa subsp. multiplex ST-6. Se han muestreado más de 18000 vegetales, (figura 1.b), 14000 de ellos se encuentran en la ZD siendo positivos 1328 árboles, también se han recogido más de 1800 muestras de insectos vectores con un $5.6 \%$ positivos en la bacteria. En la Comunidad Valenciana, el Plan de Contingencia ha establecido los muestreos tanto de material vegetal como de artrópodos vectores, tomando como referencia el mapa de riesgo potencial de Xf según los criterios de temperatura media mínima de Purcell (figura 1.a) y la implementación de una malla de muestreo de $1 \mathrm{~km}^{2}$ (figura 1.c).

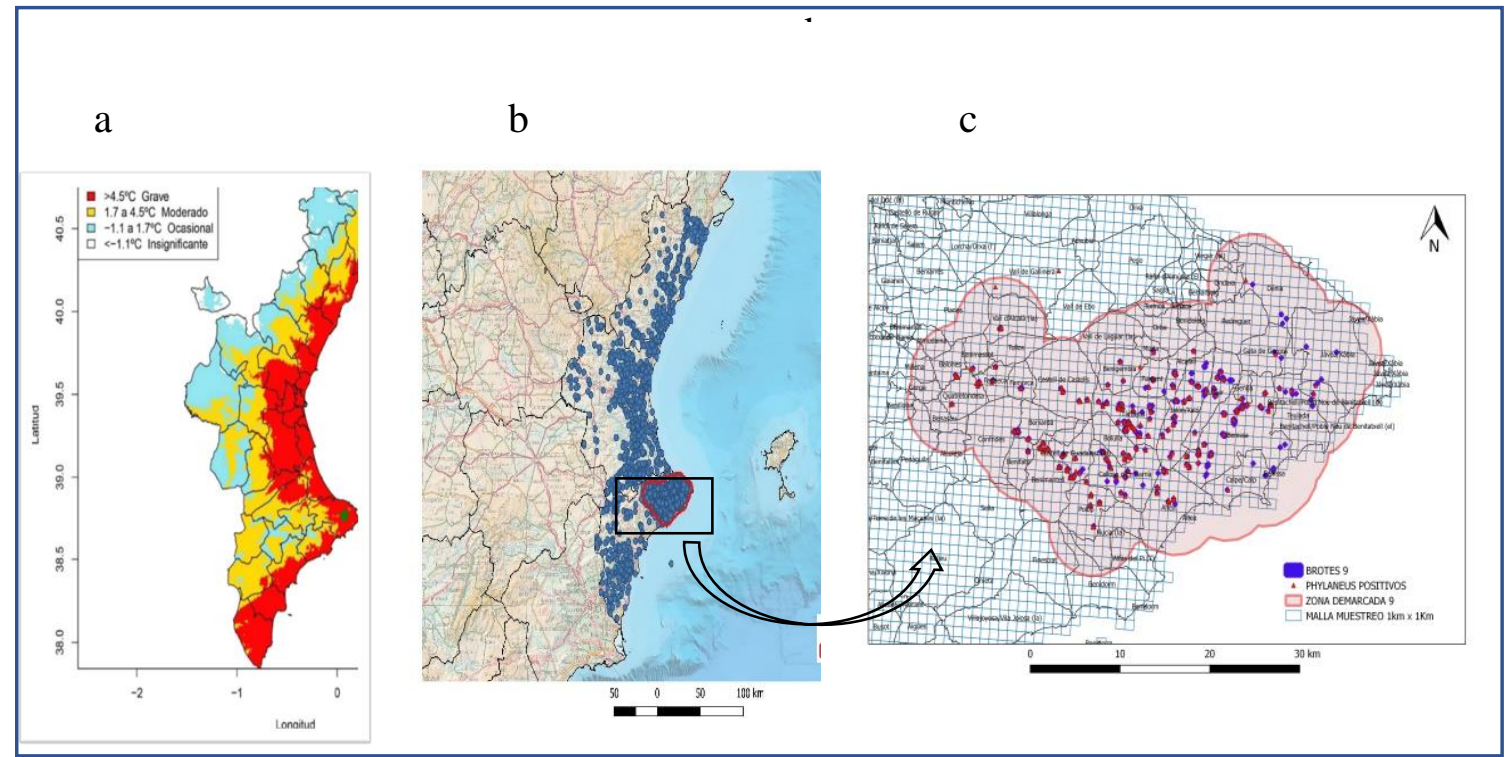

Figura 1. (a) Mapa de riesgo de Xf en función de la temperatura mínima (19712001) de la Comunidad Valenciana, según criterio de temperatura mínima de Purcell (Dirección general de agricultura y pesca 2018). (b) Muestreo de material vegetal y artrópodos vectores potenciales. (c) Malla de muestreo de material vegetal de $1 \mathrm{~km} \times 1 \mathbf{~ k m}$ y situación Zona Demarcada (ZD) y positivos de los 10 Brotes 2019 en la Comunidad Valenciana. (Elaboración propia).

\section{Estado de la cuestión}

Para estimar la distribución espacial potencial de una especie, se requiere la utilización de Modelos de Nicho Ecológico o Ecological Niche Models (ENM), que relacionan la distribución geográfica con las variables biogeográficas óptimas (Peterson et al. 2012).

Los modelos de distribución de especies caracterizan distribuciones de probabilidad basadas en el principio de que la distribución estimada de una especie debe coincidir con la conocida o deducida a partir de las condiciones ambientales donde ha sido observada. El enfoque consiste en encontrar la distribución de máxima entropía, que es la más cercana a la 


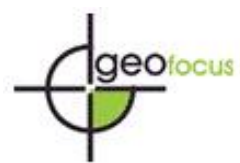

Romero Fernández, M. G. (2020): “Análisis de distribución potencial de Xylella fastidiosa subsp. multiplex ST-6 y Philaenus spumarius en el sur de la Península Ibérica mediante el modelo ecológico de nicho MaxEnt.", GeoFocus, $n^{\circ} 25$, p. 77-102. http://dx.doi.org/10.21138/GF.664

uniforme (Jaynes 1957). El procedimiento emplea algoritmos computarizados para generar mapas predictivos sobre la distribución potencial de especies en un ecosistema. Estos modelos establecen los factores ecológicos que determinan los patrones espaciales de la dispersión de un determinado organismo (Guissan y Thuiller 2005, Wisz et al. 2008).

En la construcción de los modelos hay que tener presente una serie de factores que afectan a la precisión del resultado final y que se encuentran estrechamente vinculados a la calidad de los datos de localización de la especie tanto registros de presencia como de ausencia. Un registro de presencia parece ser irrebatible salvo error en la identificación de la especie, siendo el segundo tipo de registro algo más cuestionable (Benito de Pando y Peñas de Giles 2007).

Las ausencias de una especie son más difíciles de determinar, puesto que por cuestiones de contingencia como la fragmentación del hábitat o existencia de barreras físicas y las ambientales pueden llevar a designar como ausencia una localización con características óptimas para la especie, alterando el resultado final y restando significación biológica en la interpretación del modelo (Hirzel et al. 2002). Esta circunstancia es habitual cuando se trata con especies invasoras alóctonas como Xf que no están en equilibrio con su medio y que además presentan muy baja detectabilidad que originan ausencias aparentes.

Para evaluar el rendimiento del modelo es necesario disponer de datos prueba o evaluaciones fiables con los que poder comparar los pronósticos del modelo y distinguirlos de los datos de entrenamiento o calibración que se han empleado en su desarrollo. Idealmente, los datos de prueba deberían obtenerse por separado de los datos de entrenamiento del modelo (Philips et al. 2008).

La distribución espacial de especies fitopatógenas (Hongos, Virus y Bacterias) y los parámetros bioclimáticos óptimos que facilitan su dispersión, no habían sido abordados por estos modelos hasta esta última década (Fabre et al. 2010, Aguayo et al. 2014), ya que el problema de la epidemiologia vegetal no había tenido tanto seguimiento como la distribución de las especies artrópodas que las diseminan. Feil y Purcell (2001) estudiaron las condiciones bioclimáticas óptimas de crecimiento de Xf, concluyendo que están adaptadas a inviernos suaves o moderados. El crecimiento in vitro de Xylella. fastidiosa subsp. fastidiosa es óptimo a $28^{\circ} \mathrm{C}$ y decrece a $32{ }^{\circ} \mathrm{C}, 22^{\circ} \mathrm{C}$ y $18^{\circ} \mathrm{C}$ respectivamente, no observándose crecimiento in vitro a $12{ }^{\circ} \mathrm{C}$ (figura 2 ).
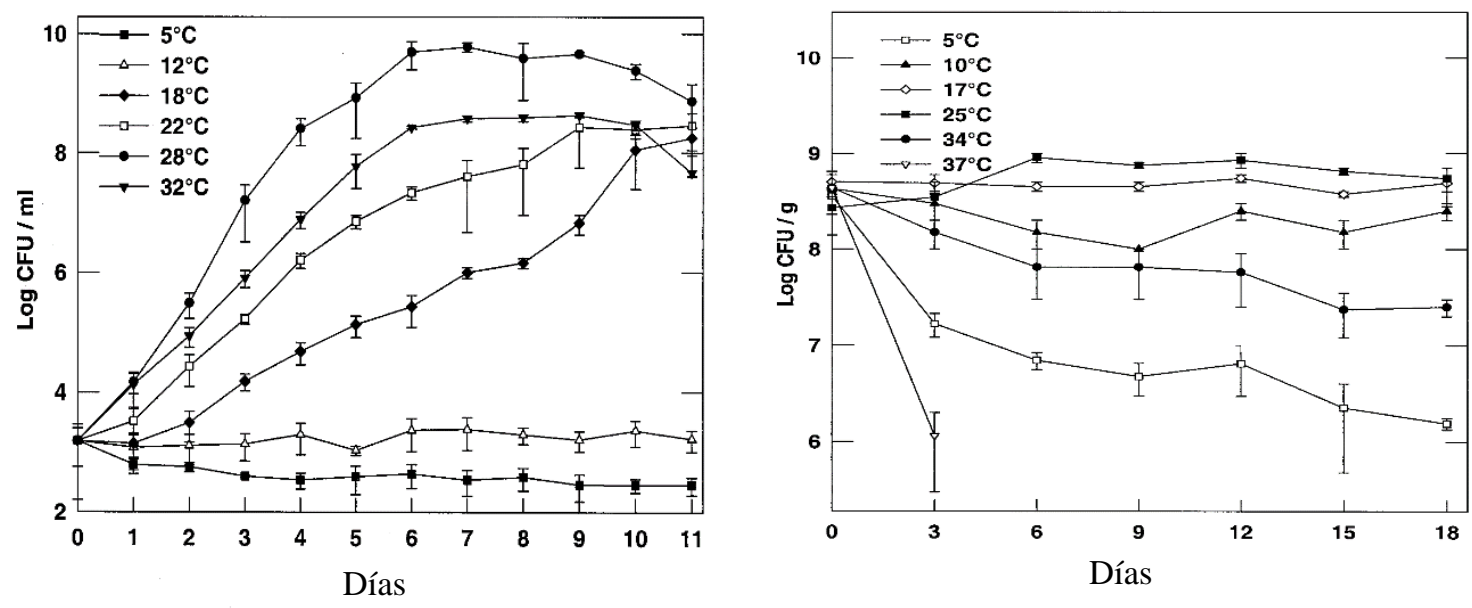

Figura 2. Crecimiento y supervivencia de $X f$ en CFU (Unidad Formadora de Colonias) en medio de cultivo durante 11 y 18 días. (Fuente: Feil y Purcell 2001). 
Romero Fernández, M. G. (2020): “Análisis de distribución potencial de Xylella fastidiosa subsp. multiplex ST-6 y Philaenus spumarius en el sur de la Península Ibérica mediante el modelo ecológico de nicho MaxEnt.", GeoFocus, $n^{\circ} 25$, p. 77-102. http://dx.doi.org/10.21138/GF.664

En plantas de vid infectadas, se ha determinado que los límites de temperatura máxima para que se produzca multiplicación de la bacteria están comprendidos entre los $17{ }^{\circ} \mathrm{C}$ y $25^{\circ} \mathrm{C}$ y que sus poblaciones en plantas infectadas de vid decrecen o cesan cuando las temperaturas están por debajo de $5{ }^{\circ} \mathrm{C}$. Por tanto, temperaturas entre $25^{\circ} \mathrm{C}$ y $32^{\circ} \mathrm{C}$ son críticas para el desarrollo de la enfermedad de Pierce de la vid. Las temperaturas por debajo de $12{ }^{\circ} \mathrm{C}$, o superiores a $34^{\circ} \mathrm{C}$, comprometen su supervivencia in planta (Feil y Purcell 2001). La capacidad de supervivencia del patógeno a las temperaturas invernales puede variar con la estirpe (subespecie/ST), y la variedad de la planta huésped que infecta (Krugner y Ledbetter 2016).

Se ha profundizado en este estudio sobre la influencia de las altas temperaturas en la incidencia de enfermedades causadas por Xf en la Península Ibérica. Estudios realizados al respecto en Estados Unidos de Norte América (EE. UU) indican que los síntomas aparecen antes y son más severos en regiones con veranos cálidos y temperaturas invernales moderadas (Winkler 1949). Para inferir zonas con condiciones climáticas favorables para la bacteria, se han utilizado diversas aproximaciones, pero estas se han realizado fundamentalmente en EE. UU y para Xylella fastidiosa subsp. fastidiosa que causa la EP en vid (Feil y Purcell 2001).

Anas et al. (2008) introduciendo las isotermas de las temperaturas mínimas invernales, propusieron para esta enfermedad los siguientes niveles de severidad y rangos térmicos sobre las temperaturas mínimas invernales, impacto severo $\left(>4,5^{\circ} \mathrm{C}\right)$, moderado $\left(1,7^{\circ} \mathrm{C}\right.$ a $\left.4,5^{\circ} \mathrm{C}\right)$, ocasional $\left(1,7^{\circ} \mathrm{C}\right.$ a $\left.-1,1^{\circ} \mathrm{C}\right)$ o raro $\left(<-1,1^{\circ} \mathrm{C}\right)$.

Hoddle (2004) utilizó el modelo CLIMEX (Sutherst y Maywald 2007) para la elaboración de mapas de distribución potencial de la enfermedad de Pierce y su vector en California (Homalodisca vitripennis), basándose en datos de Feil y Purcell (2001), concluyendo que regiones con clima tropical, semitropical, templado y mediterráneo moderado, son adecuadas para la ocurrencia de ambos organismos.

Bosso et al. (2016) realizaron un estudio de la distribución potencial de Xylella en Apulia (Italia), con MaxEnt sobre los primeros brotes confirmados que se producen en Europa, en el estudio se pretende establecer las variables eco-geográficas que favorecen la introducción y expansión de la enfermedad en la región y la potencialidad del riesgo en el resto de Italia. La subespecie es Xylella fastidiosa subsp. pauca, diferente a la manifestada en Alicante (Xylella fastidiosa subsp. multiplex). En el caso italiano el cultivo afectado es el olivo en secano, mientras que el cultivo de almendro y frutales de hueso también en secano son los más afectados en España. La humedad y las lluvias en meses secos parecen tener una alta ponderación (Por encima del $30 \%$ del total de variables) en la probabilidad de presencia de la bacteria.

Godefroid et al. (2018) establecen diferencias de la dispersión fuera del entorno de origen de tres subespecies de Xf (multiplex, fastidiosa y pauca) y de sus diferentes cepas o Sequence Type (ST). Xylella fastidiosa subsp. multiplex parece tener su hábitat en Norte América mientras que las otras dos son más afines a Centro y Sur América. Xylella fastidiosa subsp. pauca ST 53 ha infectado a los olivos italianos procedente de plantas de cafeto desde Costa Rica, mientras que Xylella fastidiosa subsp. multiplex ST-6 y ST-7 han sido introducidas en el suroeste de Francia con afinidad sobre frutales de hueso del género Prunus spp como el caso del almendro dulce (Prunus dulcis) de Alicante. Utilizando las presencias de cada una de estas subespecies y cepas e implementándolas en modelos de distribución de especies como Bioclim y MaxEnt, han realizado modelizaciones y proyecciones según los parámetros de escenarios futuros del cambio climático, con diferencias significativas para cada subespecie.

Gutiérrez Hernández y García (2018) sobre la distribución de Xf en la Península Ibérica utilizan datos de presencia de focos en las Islas Baleares con MaxEnt, a una resolución espacial 
Romero Fernández, M. G. (2020): “Análisis de distribución potencial de Xylella fastidiosa subsp. multiplex ST-6 y Philaenus spumarius en el sur de la Península Ibérica mediante el modelo ecológico de nicho MaxEnt.", GeoFocus, $n^{\circ} 25$, p. 77-102. http://dx.doi.org/10.21138/GF.664

de $1 \mathrm{~km}^{2}$. La falta de acceso a los datos públicos del estudio, no han permitido contrastar ni validar la predicción. El modelo trabaja con los positivos de Xf sin distinguir entre subespecies y cepas y no introduce el estudio de los vectores. Las variables medioambientales que más favorece la expansión de la bacteria según el estudio son las temperaturas medias de las mínimas que actúan como una barrera por debajo de la cual no hay presencia de la enfermedad.

El vector principal de $\mathrm{Xf}$ es Philaenus spumarius (Linnaeus) (Hemiptera: Aphrophoridae), insecto polífago ampliamente distribuido a nivel mundial (Drosopoulos y Remane, 2000), y medio de inoculación muy efectivo de Xf (Martelli 2016). El ciclo biológico es de metamorfosis sencilla formado por las fases de huevo, ninfa y adulto, dando lugar a una generación al año (Univoltina).

Pasa el invierno en forma de huevo, aunque se ha observado que el adulto puede sobrevivir en esta época cuando las temperaturas son suaves (Saponari et al. 2014). Tras aproximadamente 100 días de diapausa, las eclosiones de los huevos se producen al principio de la primavera (Stewart y Lees 1988) e inmediatamente después, las ninfas se desplazan hacia los primeros brotes vegetales en busca de alimento y protección, completando su desarrollo en 5-8 semanas tras pasar por cinco estadios, durante los cuales se encuentran cubiertas por una espuma mucilaginosa que les protege y les da nombre.

Los huevos de Philaenus spumarius necesitan una humedad relativa superior al $80 \%$ para poder eclosionar (Weaver y King 1954). Esta dependencia de las condiciones climáticas limita su área de dispersión a zonas templadas con elevada humedad y temperaturas superiores a $5^{\circ} \mathrm{C}$ e inferiores a $30^{\circ} \mathrm{C}$ (Bosco et al. 2018).

Las investigaciones de Cornara en Italia, considera a Philaenus spumarius el único vector potencial en Europa (Bosco et al. 2018), sin embargo, cualquier Cicadomporpha que se alimente de xilema podría teóricamente actuar como vector de la bacteria (Purcell 1989). Este podría ser el caso de las cigarras (Hemiptera: Cicadidae), muy comunes en cultivos como el olivo y descritas como vectores poco eficientes de la bacteria en América (Paião et al. 2002, Krell et al. 2007).

Una vez adquieren la bacteria, los insectos vectores adultos pueden transmitirla durante todo su período de vida (Almeida et al. 2015). Las ninfas pueden ser también portadoras de la bacteria, pero la pierden posteriormente durante la muda. Estudios realizados con varias especies de Homalodisca indican que su radio de vuelo es de aproximadamente 100 metros (Blackmer et al. 2004, Coviella et al. 2006). Los insectos vectores pueden dispersarse a largas distancias por las corrientes de viento o en los vehículos utilizados en las labores propias de la gestión de los cultivos, por lo que, desde un punto de vista espacial, puede estar relacionado con la evolución de los distintos brotes a la cercanía de estos a las vías de comunicación dentro de la ZD.

Como en la mayoría de las enfermedades vegetales, la densidad y conectividad de las plantas hospedantes en una zona, determina enormemente la velocidad de dispersión. En general, una alta densidad de plantas hospedantes favorece la dispersión, sobre todo en lo que respecta a la transmisión entre plantas contiguas (Plantegenest et al. 2007).

\section{Hipótesis y objetivos}

La hipótesis de trabajo se basa en la existencia de un patrón espacial y estacional en la dispersión del patógeno-vector (Landa, Marco-Noales 2017). El análisis de los riesgos fitopatológicos de este patógeno alóctono sobre especies agroforestales debe comprender el conocimiento de los 
Romero Fernández, M. G. (2020): “Análisis de distribución potencial de Xylella fastidiosa subsp. multiplex ST-6 y Philaenus spumarius en el sur de la Península Ibérica mediante el modelo ecológico de nicho MaxEnt.", GeoFocus, $n^{\circ} 25$, p. 77-102. http://dx.doi.org/10.21138/GF.664

patrones intra e interespecíficos abióticos y bióticos, que intervienen en su capacidad de transmisión y dispersión espacial y temporal, que permita un mayor conocimiento de la patogenicidad del sistema en el territorio de introducción, para la toma de decisiones sobre su erradicación y/o contención.

Los objetivos específicos del trabajo son:

- Estimar el riesgo potencial del patosistema, mediante el Modelo Ecológico de Nicho MaxEnt, en alta resolución espacial, para implementar mapas de muestreo precisos en la zona origen de la infección y optimizar el seguimiento de la enfermedad en la Comunidad de Valencia (Alicante). Área A1.

Validación interna y externa del modelo MaxEnt, en el área A1. Evaluación de curvas ROC y AUC del modelo y estudio de errores de omisión y comisión, mediante la correlación espacial del riesgo potencial obtenido con datos de entrenamiento de presencias y ausencias, con el riesgo potencial asociado a datos de prueba.

- Si la validación es positiva, estimar Zona de Riesgo Potencial en alta resolución espacial para la implementación en mapas de muestreo en la zona potencial de expansión hacia la Comunidad de Andalucía. Área A2.

- Caracterizar los patrones de distribución espacial de la incidencia de Xylella fastidiosa subsp. multiplex ST6 y el vector asociado Philaenus spumarius en las áreas de estudio A1 y A2, identificando las variables ambientales que las favorecen mediante un Modelo Ecológico de Nicho (MaxEnt). Generar modelos matemáticos y cartográficos de distribución potencial basados en registros de presencia-ausencia localizados en la Comunidad Valenciana, tanto de la zona demarcada y limítrofe, como de áreas más extensas fuera de ella.

\section{Materiales, datos y métodos}

\subsection{El caso de estudio.}

El marco geográfico de estudio comprende las Comunidades de Andalucía, Murcia y Valencia (Alicante). En esta última es donde se han declarado los diez brotes positivos de Xf. Se ha presentado un estudio en el área A1 (figura 3), con los muestreos tanto de bacteria como de artrópodos vectores, la proyección de dispersión potencial según el modelo MaxEnt y su validación tanto interna como externa con los puntos de prueba, y el estudio del área A2, en el que se ha realizado una predicción de presencia $\mathrm{y}$, por tanto, de riesgo potencial en la Comunidad Andaluza y de Murcia en función del área A1 (figura 3). 


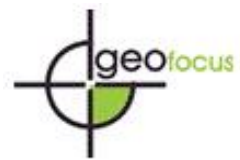

Romero Fernández, M. G. (2020): “Análisis de distribución potencial de Xylella fastidiosa subsp. multiplex ST-6 y Philaenus spumarius en el sur de la Península Ibérica mediante el modelo ecológico de nicho MaxEnt.", GeoFocus, $n^{o}$ 25, p. 77-102. http://dx.doi.org/10.21138/GF.664

\subsubsection{Delimitación espacial.}

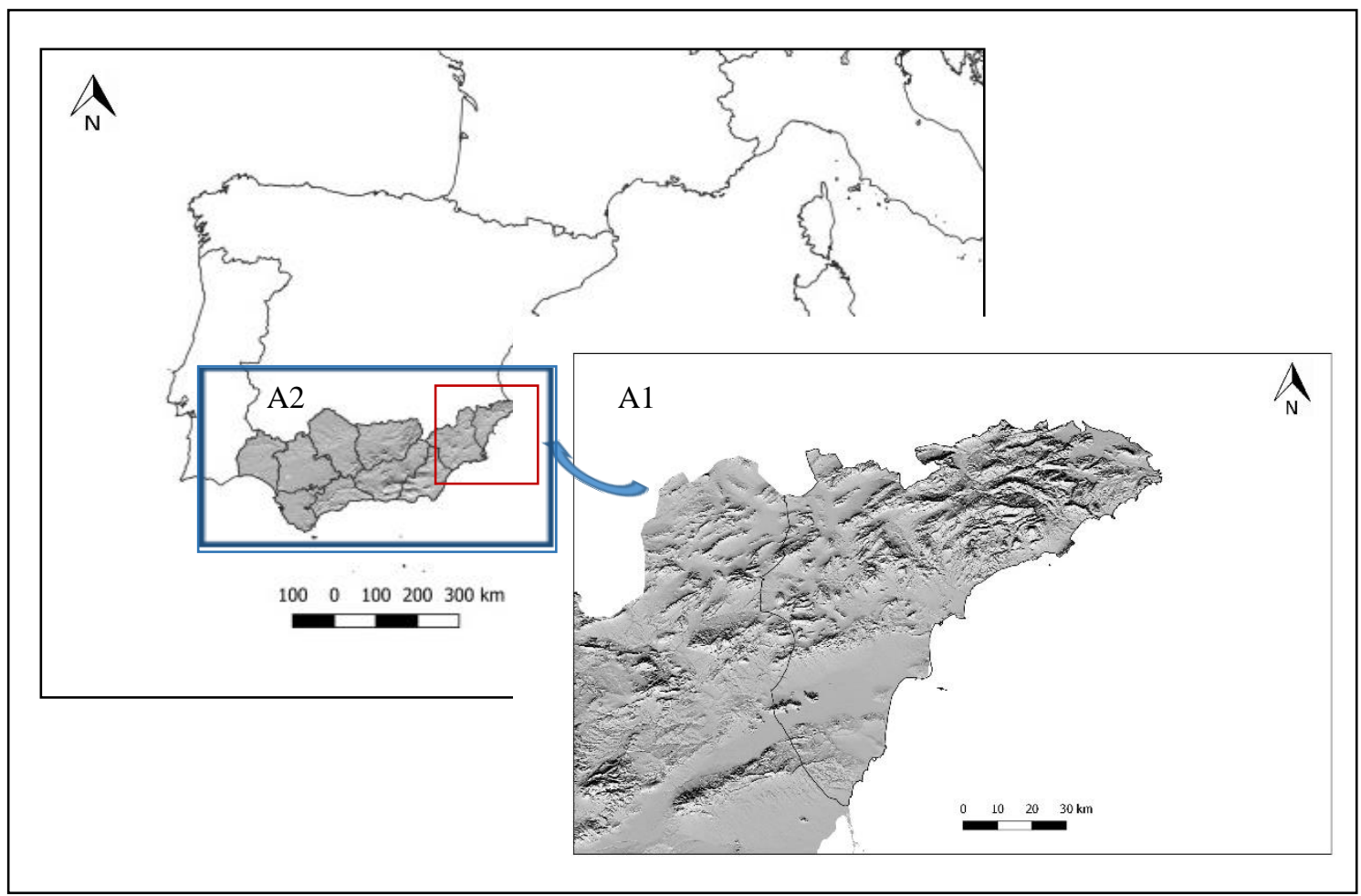

Figura 3. Áreas de estudio A1 y A2. (Elaboración propia).

\subsubsection{Delimitación temporal.}

En el caso de la Península Ibérica el primer brote declarado de Xylella fastidiosa. subsp multiplex ST-6 se produjo en julio de 2017. Existiendo hasta la fecha un total de diez brotes declarados oficialmente, el último de marzo de 2019. (Consejería de Agricultura, Servicio de Sanidad Vegetal. Diario Oficial de la Generalitat Valenciana).

\subsection{Fuentes de datos.}

4.2.1. Variables ambientales. Variables bioclimáticas y topográficas.

Las variables bioclimáticas se han obtenido del repositorio WorldClim. (www.worldclim.org), (Hijmans et al. 2005). Las variables climáticas definidas por Busby (1991) se derivan de la Temperatura y Precipitación. La información que proporciona tiene una resolución espacial mínima de $1 \mathrm{~km}^{2}$ (30 segundos de radio). Son capas ráster en formato Geotiff. y se han reescalado a una resolución espacial de 30 × 30 metros, homogéneas en tamaño y posición de los píxeles. El análisis multivariable, ha tomado cuatro de estas variables, siguiendo como base del trabajo criterios de parsimonia para la simplificación del modelo, ya que la introducción de un número mayor de variables no lo mejora. Las variables propuestas acordes a la bibliografía consultada son:

BIO5 = Temperatura Media Máxima Mes cálido. (TMAX)

BIO6 = Temperatura Media Mínima Mes frio. (TMIN)

BIO12 = Precipitación Anual. (PREC) 
Romero Fernández, M. G. (2020): “Análisis de distribución potencial de Xylella fastidiosa subsp. multiplex ST-6 y Philaenus spumarius en el sur de la Península Ibérica mediante el modelo ecológico de nicho MaxEnt.", GeoFocus, $n^{o}$ 25, p. 77-102. http://dx.doi.org/10.21138/GF.664

MDT5= Modelo Digital de Elevaciones del PNOA (MDT5)

\subsubsection{Factores bióticos, muestras de Xf y vectores artrópodos.}

Los datos de presencia de Xf detectada en la Comunidad Valenciana han sido proporcionados por el Servicio de Sanidad Vegetal dependiente de la Consejería de Agricultura, Medio Ambiente, Cambio Climático y Desarrollo Rural de la Generalitat Valenciana.

El seguimiento de la enfermedad, se ha llevado a cabo mediante la georeferenciación de las bases de datos en formato original excel con sus correspondientes coordenadas $\mathrm{X}$ e $\mathrm{Y}$, a sus respectivas capas shape, datum ETRS89, proyección UTM huso 30 extendido para hojas en los husos 29 y 31. Estas capas se han migrado a una base de datos PostGis-PostgreSQL y su implementación en un servidor Geoserver en Sistema Centos 7 (https://geographyca.us.es) utilizado como visor cartográfico web para el seguimiento de los brotes, ZD y resultados de los estudios de distribución que pueden ser consultados en el servicio WMS creado exprofeso ( http://geographyca.us.es:8080/geoserver/XYLELLA/wms?).

El total de muestras positivas (presencias) de Xf son 414 para la modelización como datos de entrenamiento y 914 como datos prueba del modelo. Los datos de presencia y ausencia del vector Philaenus spumarius, proceden de los muestreos realizados por la Consejería de Agricultura, Medio Ambiente, Cambio Climático y Desarrollo Rural Dirección General de Agricultura de la Generalitat Valenciana del año 2018 con un total de 1547 muestras, con un $6 \%$ de insectos positivos en Xylella fastidiosa subsp. multiplex. (WMS: http://geographyca.us.es:8080/geoserver/XYLELLA/wms?).

\subsection{El Modelo. MaxEnt (Phillips y Dudik 2008).}

El software ha sido seleccionado por cuestiones estrictamente comparativas ya que es el utilizado por la mayoría de bibliografía consultada sobre la distribución de Xf (Gutiérrez Hernández y García 2018, Gutiérrez Hernández y García 2019, Godefroid et al. (2018), Bosso et al. (2016)), también la rapidez el tiempo de computación y los resultados obtenidos han sido determinantes para su implementación, todo ello sin menoscabo de realizar otras modelizaciones en estudios posteriores. MaxEnt es un software de código libre (Java) cuyo propósito general es caracterizar distribuciones de probabilidad de una o varias especies basándose en el principio de que la probabilidad de su distribución debe coincidir con la conocida o deducida a partir de las condiciones ambientales dónde ha sido observada. El método no requiere datos de ausencia de la especie y puede utilizar variables tanto continuas como categóricas. Esta cuestión es a tener en cuenta ya que, aunque en teoría disponemos de datos de no ausencia, la propia dificultad del aislamiento del patógeno en laboratorio produce falsos negativos, por lo que solo utilizaremos las presencias confirmadas y las ausencias serán utilizadas para validar externamente el modelo con los errores de comisión.

El resultado del modelo expresa el valor de idoneidad del hábitat para la especie como una función de las variables ambientales. Las distintas salidas cartográficas tienen como valor de base un numero exponencial que debe cumplir la premisa que el sumatorio de todos los valores en un área de trabajo debe de ser 1 . Un valor alto de la función de distribución en una celda determinada indica que ésta presenta condiciones muy favorables para la presencia de la especie. MaxEnt puede utilizar variables cualitativas, otorgando a cada valor de la variable un peso relativo al número total de puntos de presencia que contiene. El programa proporciona las curvas de respuesta de la especie ante las distintas variables ambientales y estima la importancia de cada variable en la distribución de la especie. 
Romero Fernández, M. G. (2020): “Análisis de distribución potencial de Xylella fastidiosa subsp. multiplex ST-6 y Philaenus spumarius en el sur de la Península Ibérica mediante el modelo ecológico de nicho MaxEnt.", GeoFocus, $n^{\circ} 25$, p. 77-102. http://dx.doi.org/10.21138/GF.664

Para evaluar el rendimiento y validar el modelo, es necesario disponer de datos no introducidos en el algoritmo con los que poder comparar los pronósticos de probabilidad (Datos prueba). El sistema tiene una validación interna del rendimiento y en el caso de no disponer de datos prueba, le permite dividir los datos disponibles en dos subconjuntos, uno de entrenamiento y otro de prueba. La más simple y común consiste en agrupar los datos aleatoriamente, extrayendo el $70 \%$ de los datos para el conjunto de datos de entrenamiento y el $30 \%$ para el conjunto de datos de prueba. Esta modelización se puede repetir tantas veces se estime oportuno y en cada modelización los datos son diferentes y se extraen al azar. En el caso de estudio se dispone de un muestreo de datos prueba (décimo brote con 914 presencias) no implementados en la modelización con la que poder realizar tanto validaciones internas como externas, ya que el software permite utilizar estos datos externos en lugar de extraer un porcentaje aleatorio de las presencias de entrenamiento.

Todos los modelos obtenidos se someten al estadístico del sistema y se obtiene un rendimiento predictivo resumido en una matriz de confusión (figura 4). La matriz de confusión recoge las frecuencias de cada uno de los cuatro tipos posibles de pronóstico y nos indica el error que ha cometido el modelo en su predicción.

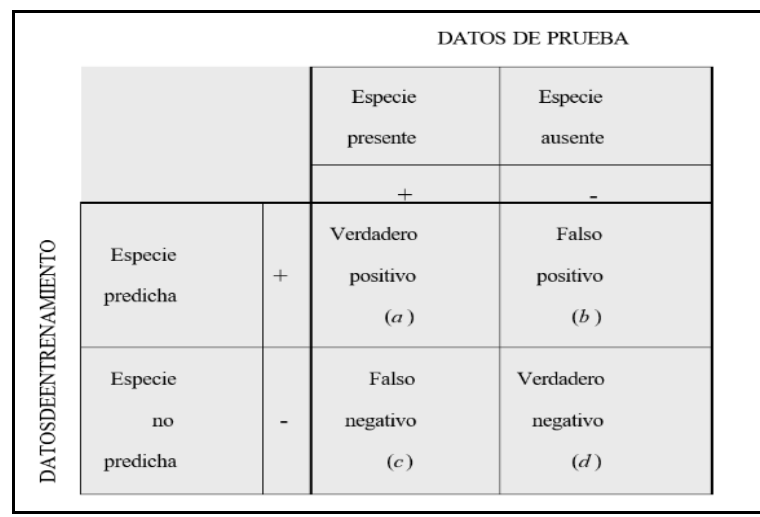

Figura 4. Matriz de confusión sobre las predicciones del modelo MaxEnt (Fuente: Martínez 2014).

Los falsos positivos (b) provocan un error de comisión real o aparente, ya que puede significar o una sobrepredicción del modelo o una predicción de nicho potencial de la especie. Los falsos negativos (c) provocan una infrapredicción y se denomina error de omisión y es mucho más importante, pues no predice lugares de presencia que pueden ser de gran importancia para la supervivencia de la población (Merow et al. 2013).

La validación de la capacidad predictiva del modelo se realiza aplicando una prueba estadística Kappa (k) sobre la matriz de confusión, que estima la exactitud del modelo y tiene en cuenta la proporción de predicciones correctas que cabría esperar aleatoriamente. Cuando solamente se usan datos de presencia, se puede calcular la proporción de ocurrencias observadas correctamente predichas, este estadístico se denomina Sensibilidad o "Fracción de verdaderos positivos" $(\mathrm{a} /(\mathrm{a}+\mathrm{c}))$. Por otra parte, podemos calcular la Tasa de omisión o "Fracción de falsos positivos" $(\mathrm{c} /(\mathrm{a}+\mathrm{c}))$.

Otro estadístico derivado de la matriz de confusión es la proporción de ausencias observadas que son correctamente predichas, $(\mathrm{d} /(\mathrm{b}+\mathrm{d}))$, se denomina Especificidad o "Fracción de verdaderos negativos", y adquiere una gran importancia en la selección del umbral de presencias y en el análisis de las curvas ROC (Receiver Operating Characteristic). 


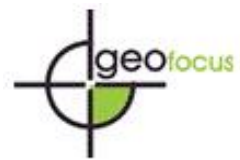

Romero Fernández, M. G. (2020): “Análisis de distribución potencial de Xylella fastidiosa subsp. multiplex ST-6 y Philaenus spumarius en el sur de la Península Ibérica mediante el modelo ecológico de nicho MaxEnt.", GeoFocus, $n^{\circ} 25$, p. 77-102. http://dx.doi.org/10.21138/GF.664

Los estadísticos AUC (Area Under Curve), área bajo la curva y la curva ROC se obtienen al enfrentar la sensibilidad frente a "1-Especificidad" es decir, la proporción de verdaderos positivos con falsos positivos a lo largo de todos los posibles umbrales. Se utilizan la sensibilidad y la especificidad porque estas dos medidas tienen en cuenta los cuatro elementos de la matriz de confusión. Por conveniencia se calcula "1-Especificidad" para que la sensibilidad y la especificidad varíen en la misma dirección cuando se ajusta el umbral (figura $5)$.

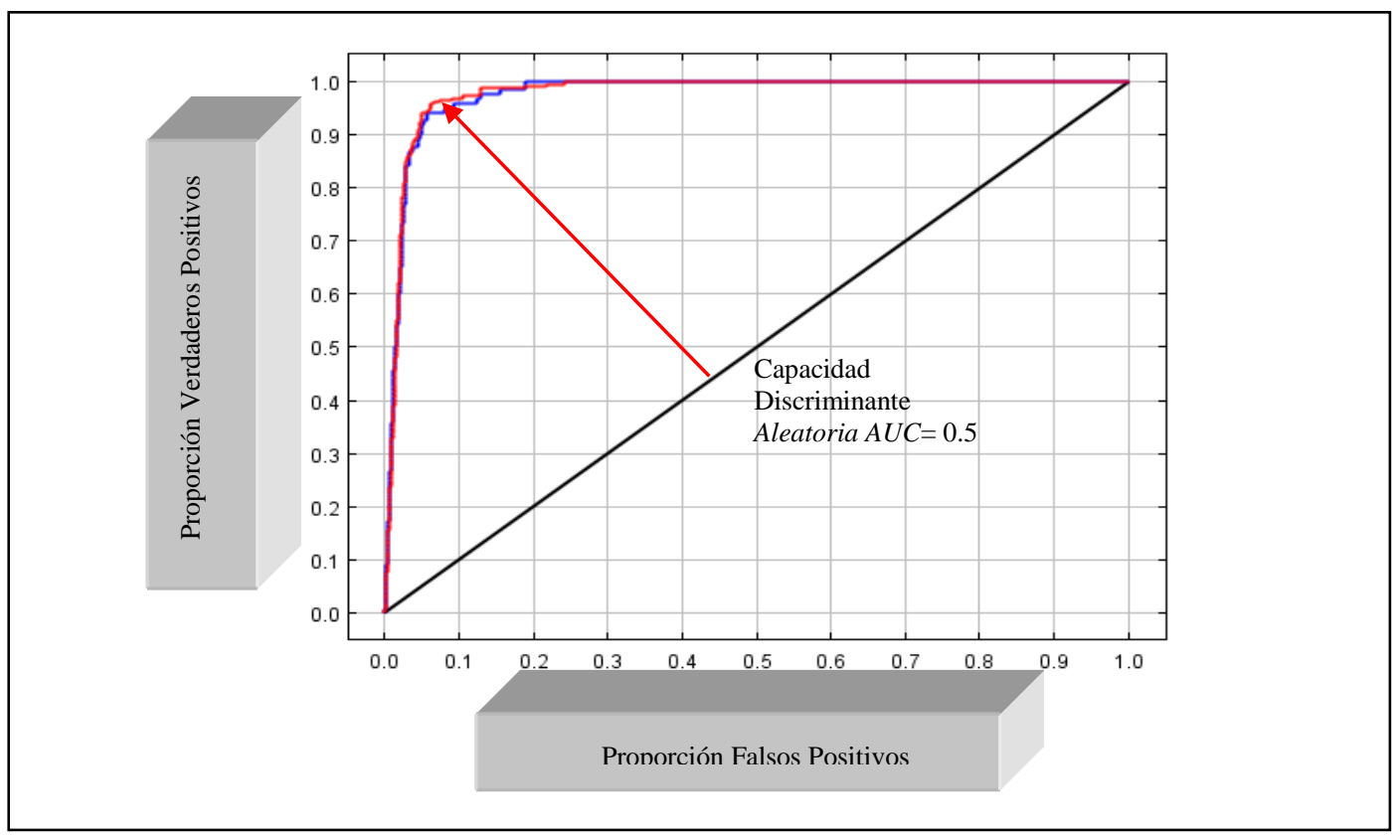

Figura 5. Curva ROC y estadístico AUC del modelo MaxEnt. (Elaboración propia).

La bondad de los modelos se ha estimado mediante el estadístico AUC, cuyos valores oscilan entre 0.5 y 1 . Un valor de 0.5 significa que el modelo no tiene capacidad discriminante (es equivalente a una clasificación al azar), en el otro extremo, un valor de 1 indica que el modelo ha separado presencias de ausencias con un ajuste perfecto, sin errores.

La preselección de variables candidatas para el modelado de la distribución de las especies se debe hacer antes del modelado (Elith et al. 2011), por lo que es necesario realizar un análisis multivariante de las variables ambientales (Cruz-Cárdenas et al. 2014) para eliminar la autocorrelación entre covariables, y por lo tanto, evitar la inestabilidad en el modelado. Se han empleado el coeficiente de correlación de Pearson (Kumar y Stohlgren 2009), donde se evalúa la multicolinealidad, y la regresión múltiple, que utiliza el factor de inflación de la varianza (Der y Everitt 2002).

Los parámetros de la modelizacion se han basado en una salida RAW del modelo, ya que presenta los valores de probabilidad puros sin ninguna transformación por defecto del sistema. Habitualmente se suele utilizar una salida logística que reescala los valores del 0 al 1directamente (Como \% de probabilidad) pero tiene el inconveniente de que hay que conocer previamente la prevalencia de la especie, si no es así el sistema le administra por defecto un valor 0.5 que puede inducir a errores (Benito de Pando 2015). En el caso de estudio esta prevalencia es desconocida al tratarse de una especie invasora de reciente introducción. La salida RAW debe someterse a una reclasificación de sus valores primero linealizándola 


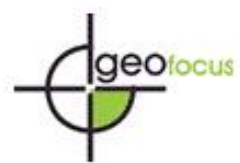

Romero Fernández, M. G. (2020): “Análisis de distribución potencial de Xylella fastidiosa subsp. multiplex ST-6 y Philaenus spumarius en el sur de la Península Ibérica mediante el modelo ecológico de nicho MaxEnt.", GeoFocus, $n^{o}$ 25, p. 77-102. http://dx.doi.org/10.21138/GF.664

mediante una transformación logarítmica natural y después a una segunda reclasificación a valores 0 al 1.

Se ha introducido un valor de regularización superior a 1 que ha evitado salidas sobreajustadas de las curvas de respuesta de la especie con las variables ambientales y se le ha solicitado que se represente la importancia relativa y absoluta de estas variables en la modelización mediante sus respectivas curvas de respuesta y estadísticos (Jacknife).

Para la modelización se han introducido los positivos correspondientes a los nueve primeros brotes con un total de 414 puntos, (Datos de entrenamiento). Con respecto a la probabilidad de presencia del vector se ha realizado una modelización independiente al de la bacteria, empleando MaxEnt, implementando los más de 1500 puntos disponibles. Este modelo se ha correlacionado con el modelo de la distribución de la probabilidad de presencia de la bacteria mediante un análisis multivariable de ambos ráster en Qgis, con una correlación del $95 \%$ de ambas probabilidades y se ha obtenido un único mapa de Riesgos del patosistema que es el resultado de fusionar ambas probabilidades. Esta parametrización esta asequible en la pagina web: https://geographyca.us.es/CARTOXYLELLA/ESTUDIO\%20DISTRIBUCION.html

\section{Descripción y análisis de resultados}

5.1. Salida cartográfica RAW del modelo transformado y reescalado 0 a 1 de probabilidad de presencia del Patosistema en el área A1 (figura 7). Salida Curvas ROC y estadístico AUC (figura 8).

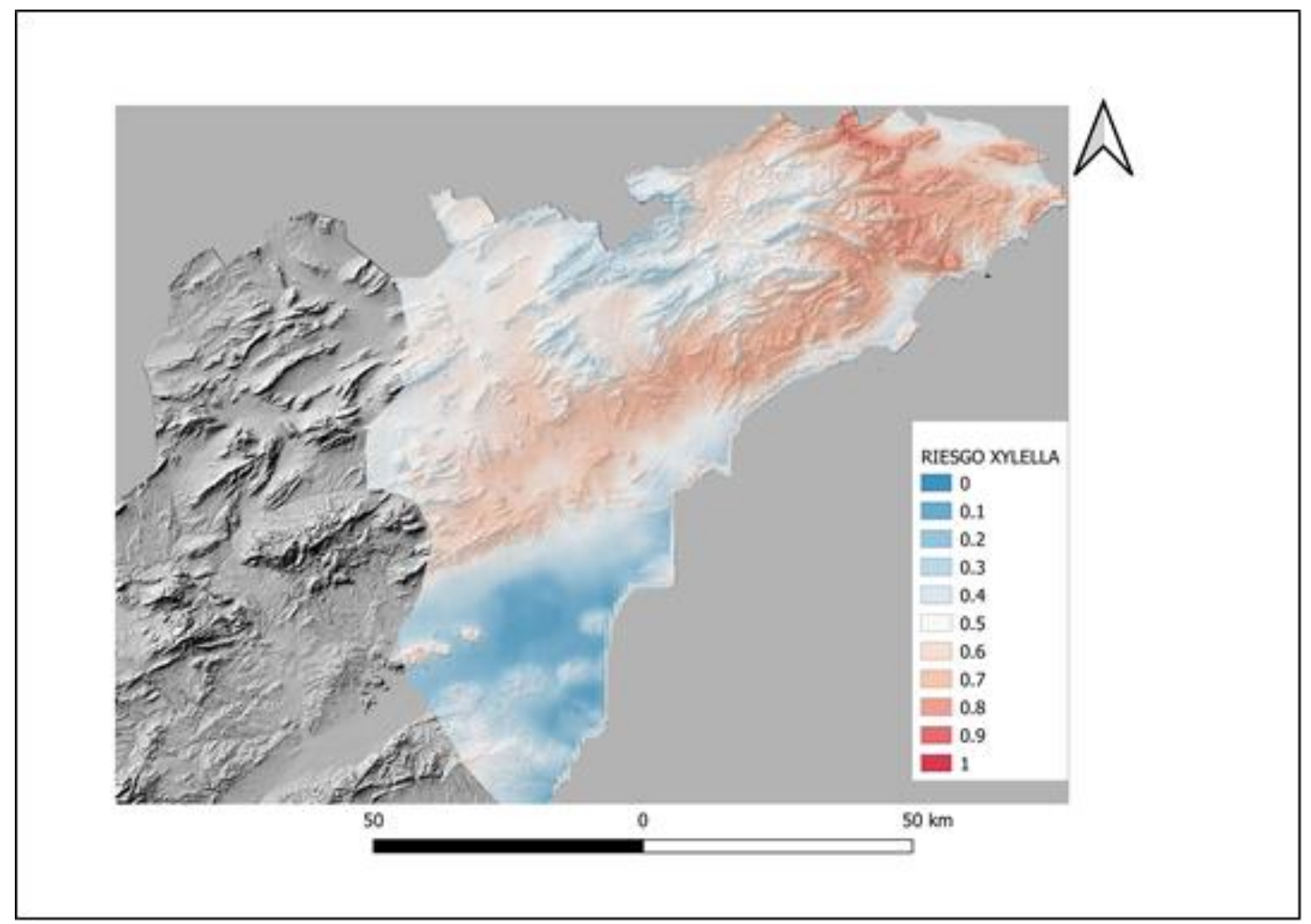

Figura 7. Probabilidad presencia del patosistema en área A1 valores de 0 a 1.

(Elaboración propia). 
Romero Fernández, M. G. (2020): “Análisis de distribución potencial de Xylella fastidiosa subsp. multiplex ST-6 y Philaenus spumarius en el sur de la Península Ibérica mediante el modelo ecológico de nicho MaxEnt.", GeoFocus, $n^{\circ} 25$, p. 77-102. http://dx.doi.org/10.21138/GF.664

1

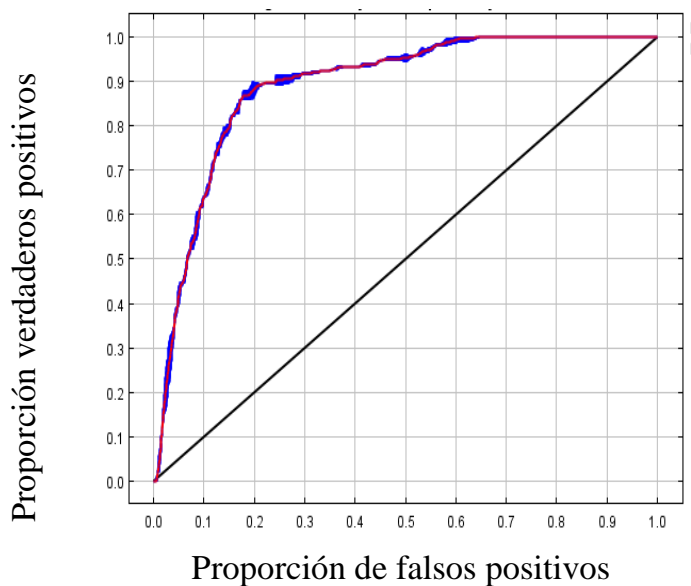

2

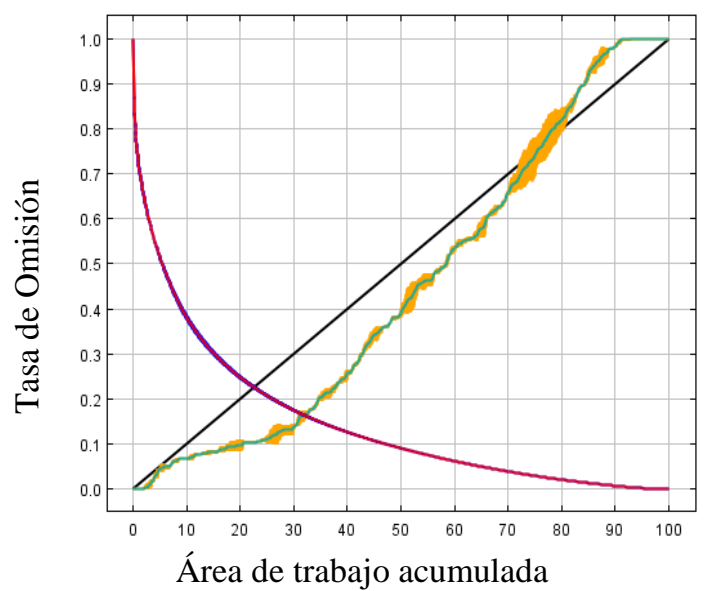

Figura 8. (1) Gráfico curva ROC y estadístico AUC área A1, con valores que rondan el $90 \%$. (2) Curva de Tasa de omisión de entrenamiento ajustada a la esperada (Línea negra). (Elaboración propia).

5.2. Salida cartográfica RAW del modelo, transformado y reescalado de 0 a 1 de probabilidad presencia Patosistema en el área A2 (figura 9). Salida grafica curvas ROC y estadísticos AUC (figura 10).

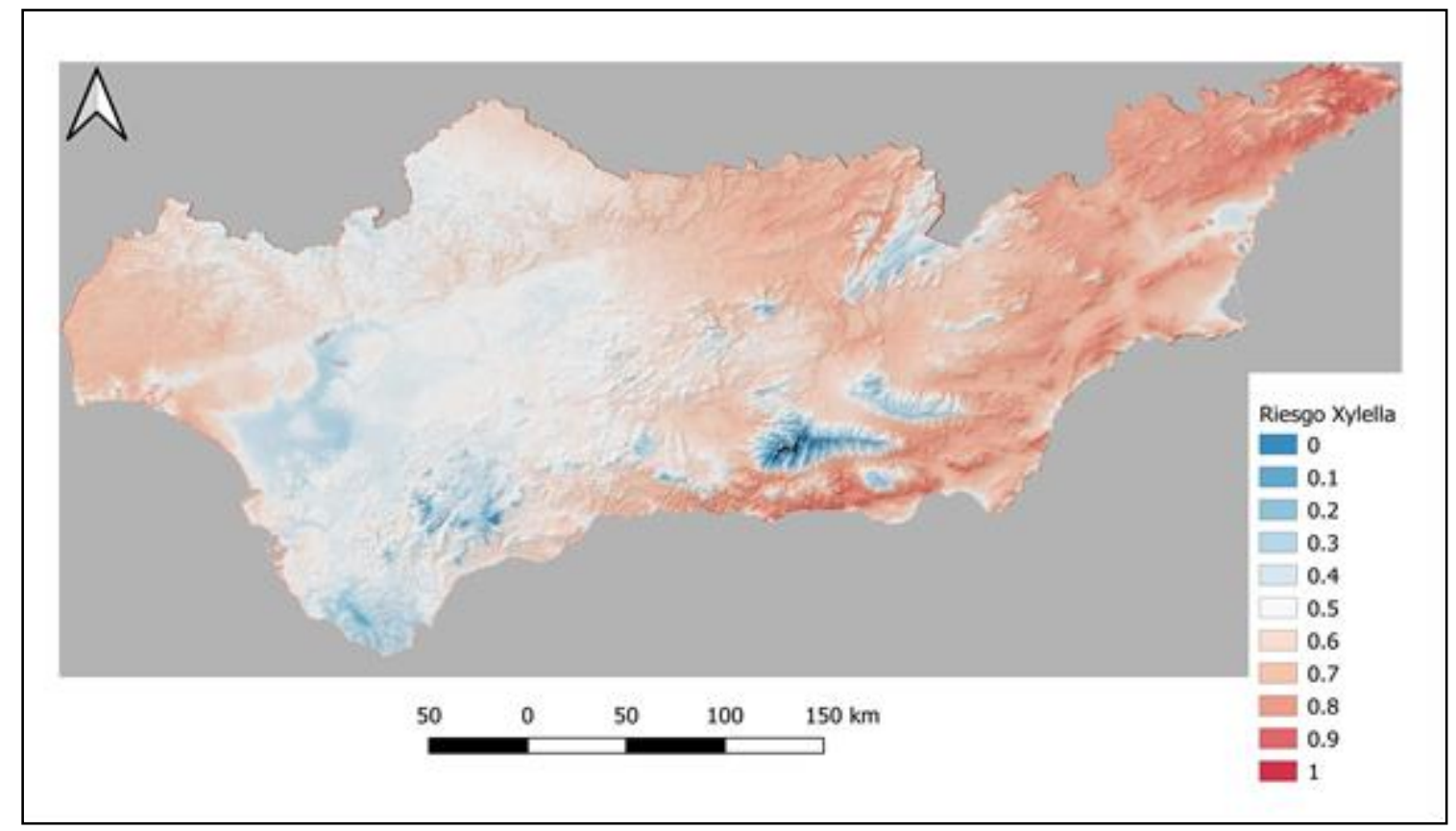

Figura 9. Probabilidad presencia del patosistema en área A2. (Elaboración propia). 


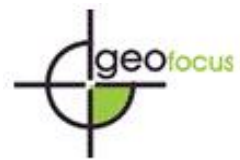

Romero Fernández, M. G. (2020): “Análisis de distribución potencial de Xylella fastidiosa subsp. multiplex ST-6 y Philaenus spumarius en el sur de la Península Ibérica mediante el modelo ecológico de nicho MaxEnt.", GeoFocus, $n^{\circ} 25$, p. 77-102. http://dx.doi.org/10.21138/GF.664
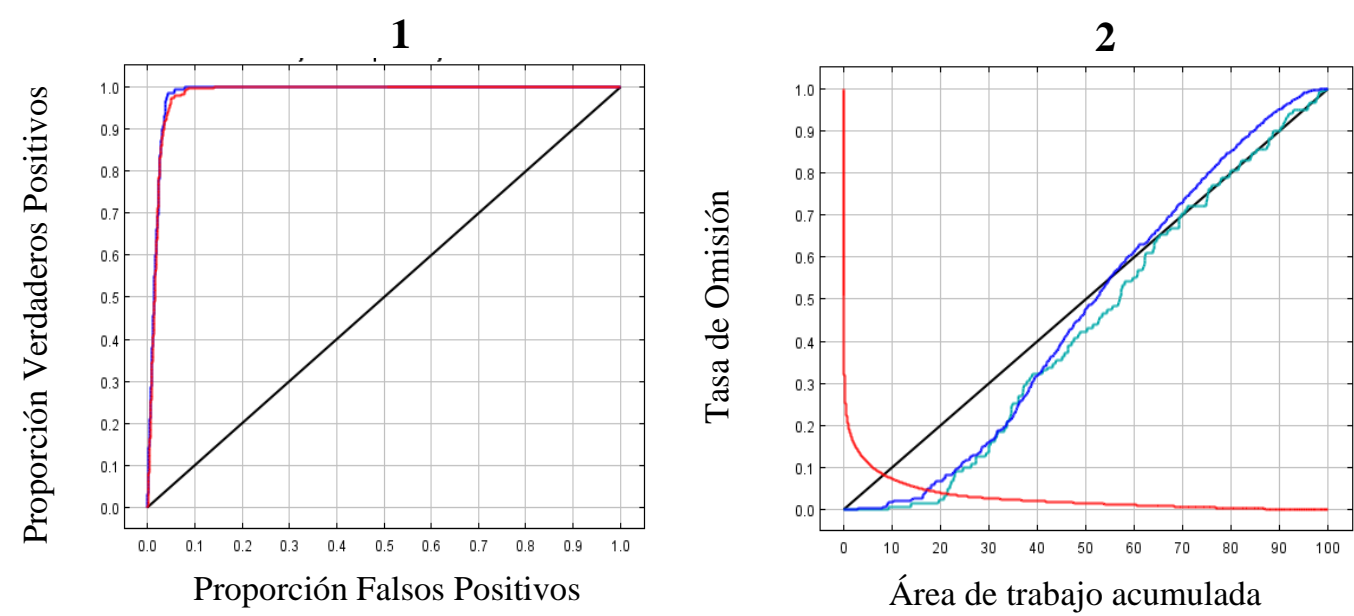

Figura 10. (1) Gráfico curva ROC y estadístico AUC área A2 con valores que rondan el $99 \%$. (2) Omisión de entrenamiento ajustada a la esperada (Liena negra). (Elaboración propia).

\subsection{El estudio estadístico de las muestras. Validación externa (Área A1).}

La aparición en marzo de 2019 de un décimo brote ha permitido realizar una validación externa a la realizada por MaxEnt, con puntos no introducidos en la elaboración del modelo. Se ha extraído la variable probabilidad al modelo, de todos los puntos muestreados como positivos tanto de los datos de entrenamiento con 414 muestras como de los datos de prueba con 914 muestras y se han elaborado sus respectivos histogramas de frecuencias con el software RCommander 3.5.3 (figura 11) para comprobar la coherencia de ambos conjuntos de datos (Ajuste y Prueba). Se ha realizado un estudio de los errores de omisión con los datos de presencia y un estudio de error de comisión con los muestreos con no presencia.

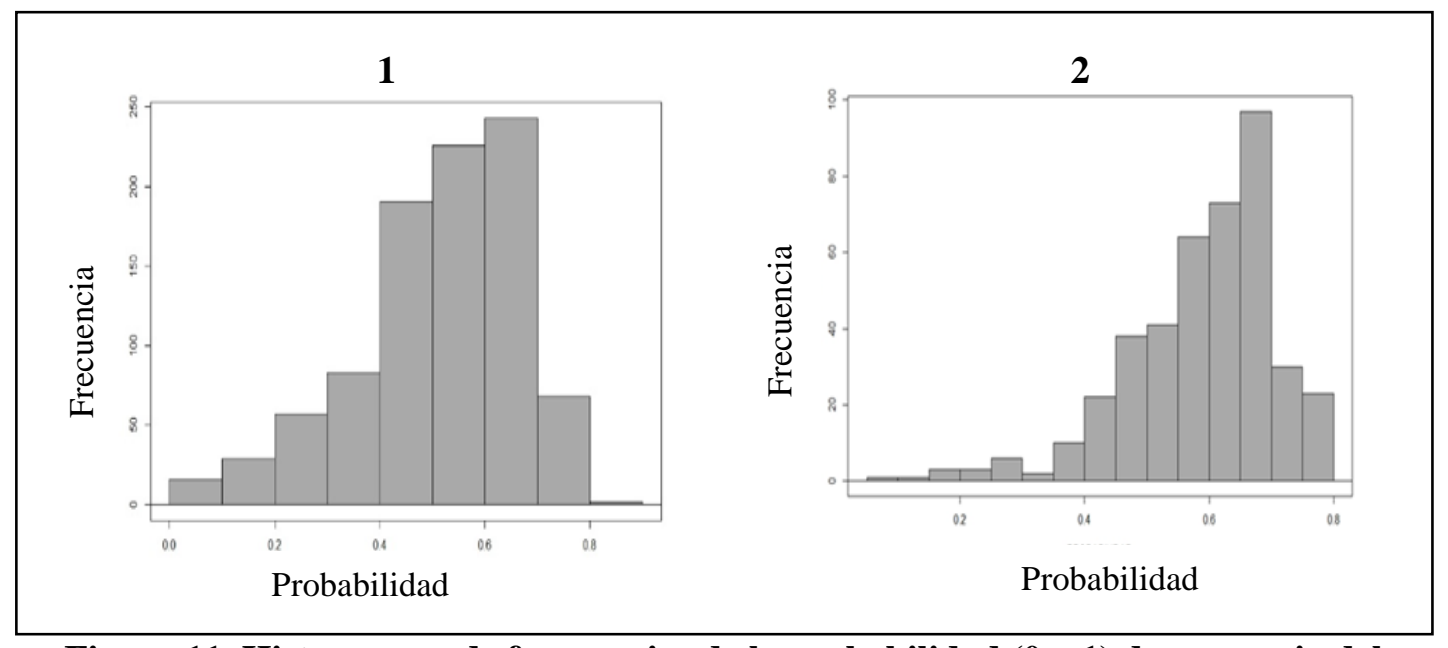

Figura 11. Histogramas de frecuencias de la probabilidad ( 0 a 1$)$ de presencia del

Patosistema asociada a los datos de entrenamiento (1) y datos de prueba (2). Se aprecia la gran cantidad de valores por encima de la mediana (50\%). (Elaboración propia).

Se ha obtenido una validación ajustada al modelo, con el $80 \%$ de los datos de prueba con riesgos de probabilidad asignados como altos (Riesgo > $70 \%$ ). El error de omisión es del 


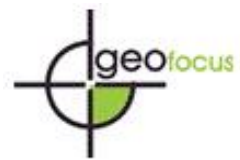

Romero Fernández, M. G. (2020): “Análisis de distribución potencial de Xylella fastidiosa subsp. multiplex ST-6 y Philaenus spumarius en el sur de la Península Ibérica mediante el modelo ecológico de nicho MaxEnt.", GeoFocus, $n^{o}$ 25, p. 77-102. http://dx.doi.org/10.21138/GF.664

$20 \%$ para esta ventana. Para una ventana menor (Riesgo>60 \%) la omisión desciende hasta un $10 \%$, semejante al mostrado por la validación interna del modelo MaxEnt en sus curvas AUC $(<10 \%)$ y Omisión ajustada (figura 8).

El estudio ha reflejado que hay un error de comisión de aproximadamente un $10 \%$, (Falsos positivos) los datos de prueba utilizados han sido los muestreos negativos y categorizados como no presencia. Estos falsos positivos están en zonas clasificadas con más de un $80 \%$ de Riesgo de probabilidad de albergar la bacteria, mientras que el resto de los datos $(90 \%)$ son verdaderos negativos al ocupar celdas categorizadas como de baja o nula probabilidad (Riesgo<20\%)

En el siguiente gráfico (figuras 12. a.b.c.d.) se muestran los valores extraídos de los 914 puntos para cada una de las variables ambientales implementadas en el modelo y correlacionarlas con el valor correspondiente al riesgo de presencia, pudiéndose observar los límites mínimos y máximos de cada variable ambiental, similares a las obtenidas en las curvas de respuesta del modelo, los valores de la probabilidad están en logaritmo natural en ordenadas y las variables en abscisas en sus respectivas unidades.

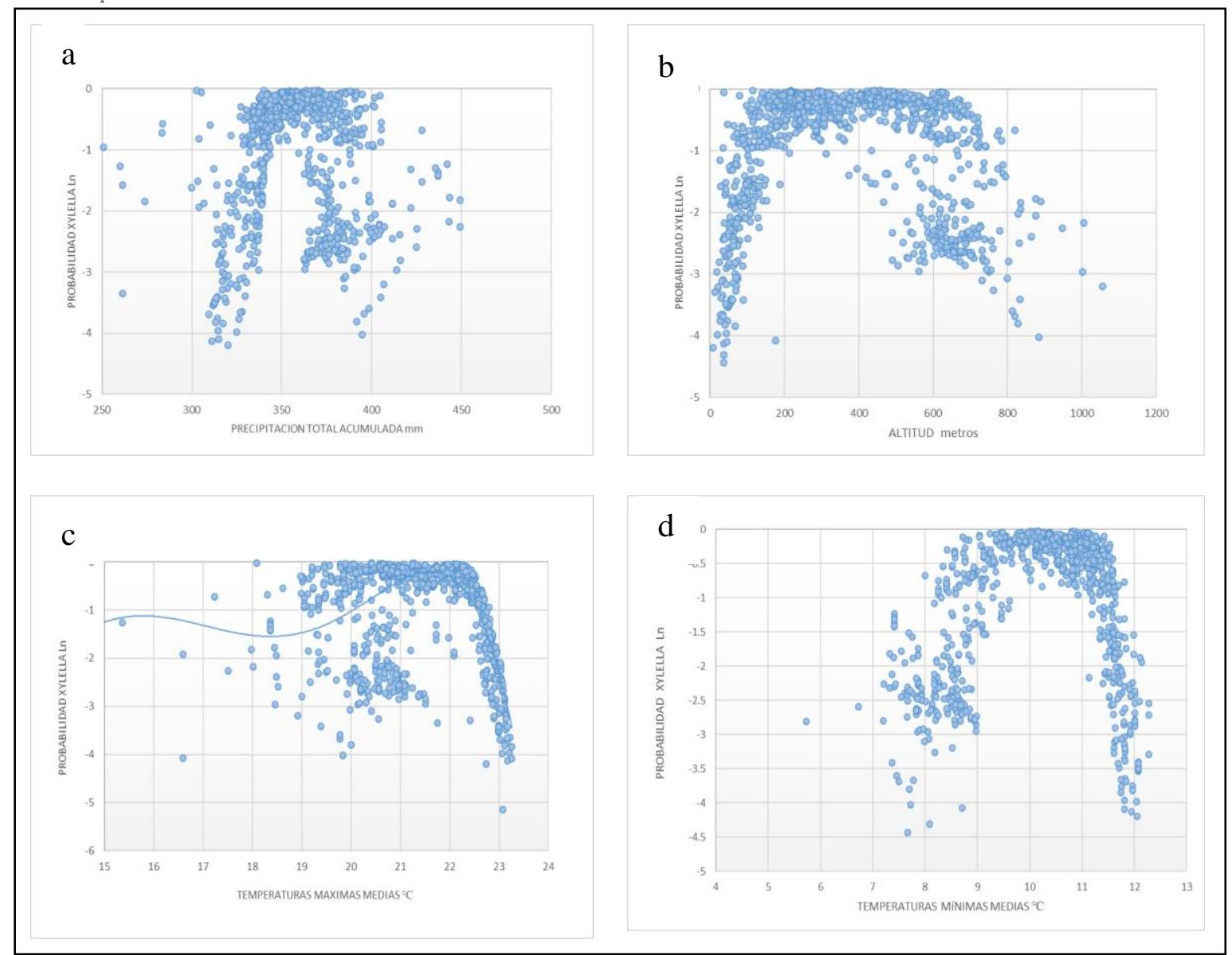

Figura 12. Correlación dispersión de las variables ambientales (Valores en sus magnitudes originales) en abscisas, con respecto al Riesgo Potencial estimado de Xf (valores en Ln) en ordenadas. (Elaboración Propia).

a. Precipitación Total. (PREC) en mm.

b. Alturas. (MDT) en metros. c. Temperatura Media Máximas. (TMAX) en ${ }^{\circ} \mathrm{C}$. d. Temperatura Media Mínimas. (TMIN) en ${ }^{\circ} \mathrm{C}$. 
Romero Fernández, M. G. (2020): “Análisis de distribución potencial de Xylella fastidiosa subsp. multiplex ST-6 y Philaenus spumarius en el sur de la Península Ibérica mediante el modelo ecológico de nicho MaxEnt.", GeoFocus, $n^{o}$ 25, p. 77-102. http://dx.doi.org/10.21138/GF.664

\subsection{Modelización matemática}

Validado el modelo por sus estadísticos internos y externos, se ha establecido una fórmula matemática de predicción de MaxEnt para realizar una segunda evaluación externa. Para ello se ha utilizado el módulo Point Sampling Tools de Qgis que permite extraer los valores de cada una de las variables de múltiples capas raster acorde a una nube de puntos en formato vectorial. Este módulo produce una tabla de texto (csv.) compatible con excell. De esta manera se han obtenido dos tablas, una para los puntos de entrenamiento del modelo (9 primeros brotes) con la que se ha elaborado la fórmula matemática y que presenta cinco columnas, la primera con el riesgo o probabilidad de presencia (variable dependiente) y las cuatro restantes con los valores de las variables ambientales del modelo (variables independientes). La segunda tabla de prueba corresponde a los puntos del último brote a la que se le han extraído los valores correspondientes de Riesgo y las variables ambientales del modelo

cartográfico solo para estos puntos con cinco columnas homologas a la anterior.

La tabla de entrenamiento ha sido analizada con el estadístico de R-Commander 3.5.3 para realizar un estudio de regresión lineal y obtener los coeficientes de las variables independientes y obtener una ecuación (Tabla1). Si bien el estadístico solo funciona con modelos lineales, se puede operar con modelos no lineales que pudieran presentar un mejor ajuste a los datos de entrada. Para ello se aplica logaritmos tanto a la variable dependiente como a las variables independientes para obtener un modelo múltiple potencial o solo aplicando logaritmo a la variable dependiente en una modelización múltiple exponencial. Se ha estimado el modelo potencial como el óptimo con un coeficiente de correlación ( $\mathrm{R}=0.85)$.

Tabla 1. Resultados regresión lineal múltiple procedente de los datos de entrenamiento, Los coeficientes son los correspondientes a la columna Estimate.

\begin{tabular}{|c|c|c|c|c|}
\hline & Estimate & Std. Error & $\mathrm{t}$ value & $\operatorname{Pr}(>|t|)$ \\
\hline (Intercept) & -21.60100 & 1.46474 & -14.75 & $<2 \mathrm{e}-16 * * *$ \\
\hline MDT & 0.95205 & 0.03436 & 27.71 & $<2 \mathrm{e}-16 * * *$ \\
\hline PREC & 3.77220 & 0.31380 & 12.02 & $<2 \mathrm{e}-16 * * *$ \\
\hline TMAX & -12.49730 & 0.45023 & -27.76 & $<2 \mathrm{e}-16 * * *$ \\
\hline TMIN & 13.52239 & 0.27839 & 48.57 & $<2 \mathrm{e}-16 * * *$ \\
\hline \multicolumn{5}{|c|}{$\begin{array}{l}\text { Residual standard error (SSE): } 0.551 \text { on } 1361 \text { degrees of freedom } \\
\text { Multiple R-squared: } 0.856 \\
\text { Adjusted R-squared: } 0.86 \\
\text { F-statistic: } 762.9 \text { on } 4 \text { and } 1361 \text { DF, p-value: }<2.2 \mathrm{e}-16\end{array}$} \\
\hline
\end{tabular}

Formula Obtenida:

$$
\ln (\text { Probabilidad })=-21.60+0.95 \ln \mathrm{MDT}+3.77 \ln \text { PREC+ } 13.52 \ln \text { TMIN }-12.49 \ln \text { TMAX }
$$

La transformación logarítmica introduce un sesgo (subestimación) en los cálculos (Baskerville 1972). Para la eliminación de este sesgo, el resultado final debe ser multiplicado por un factor de corrección (FC), calculado a partir del error estándar de la estimación (Residual Standard Error en R-commander) (SEE). Este valor del coeficiente de corrección, para un modelo potencial es calculado según la siguiente expresión. (Wood 1986). 


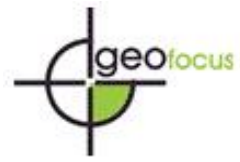

Romero Fernández, M. G. (2020): “Análisis de distribución potencial de Xylella fastidiosa subsp. multiplex ST-6 y Philaenus spumarius en el sur de la Península Ibérica mediante el modelo ecológico de nicho MaxEnt.", GeoFocus, $n^{o} 25$, p. 77-102. http://dx.doi.org/10.21138/GF.664

$$
\begin{aligned}
& \mathrm{CF}=\mathrm{e}^{\beta} \\
& \beta=\mathrm{SSE}^{2} / 2 \\
& \text { Probabilidad }=\operatorname{EXP}(-21.60) * \text { MDT }^{0.95} * \text { PREC }^{3.77} * \mathrm{TMIN}^{13.52 *} \mathrm{TMAX}^{-12.49 *} \mathrm{CF}(1.16)
\end{aligned}
$$

De esta forma tendremos dos valores de riesgo para los datos prueba, uno correspondiente a la extracción de la tabla de prueba del mapa y otro el calculado por la fórmula matemática, ambas probabilidades son sometidas a una regresión estadística y se correlacionan sus valores para comprobar el grado predictivo del modelo (figura 13).

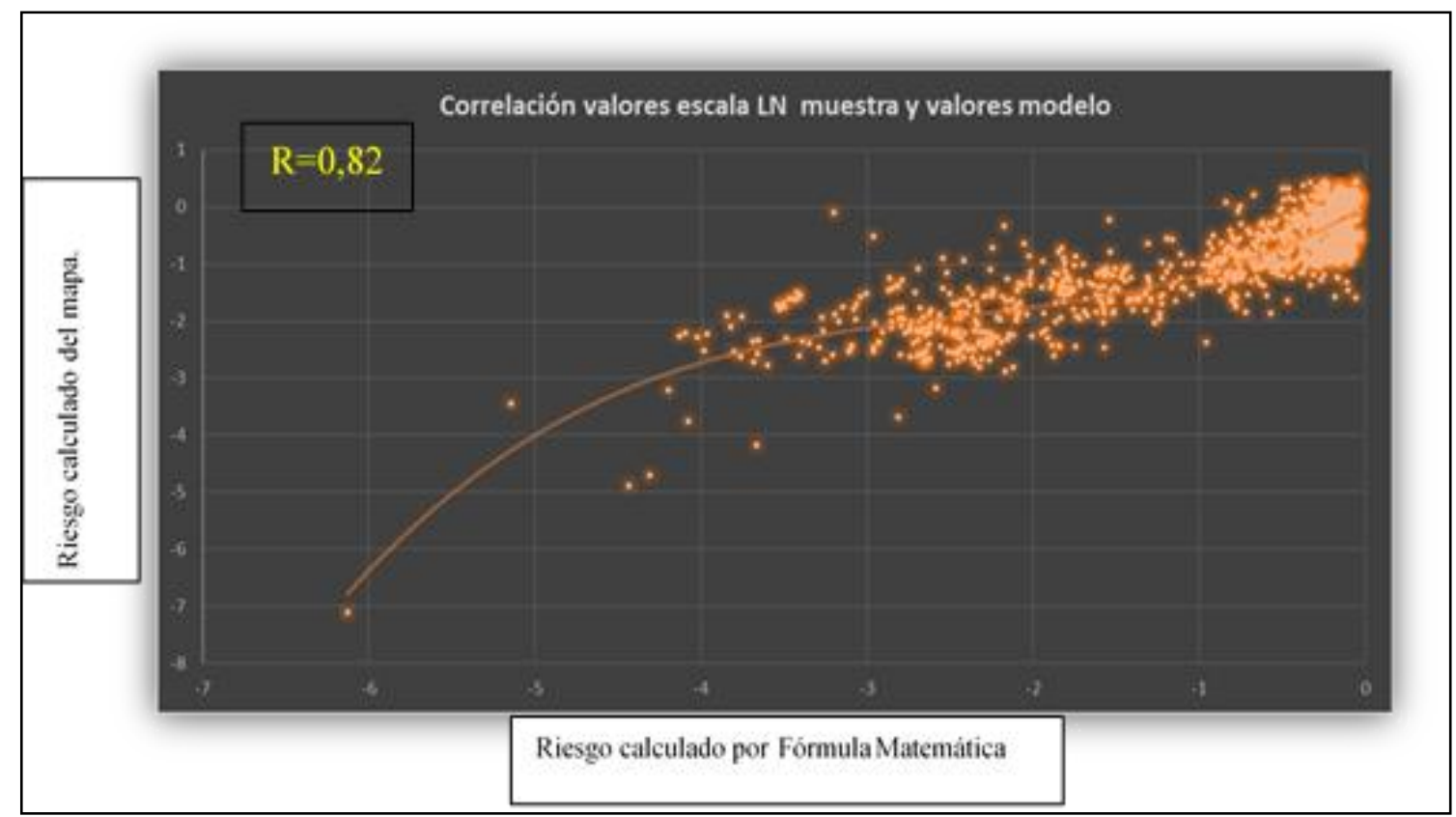

Figura 13. Diagrama de regresión de variable probabilidad de presencia de los datos prueba, calculada por el modelo matemático y valor del modelo MaxEnt. Coeficiente de Correlación $\mathbf{R}=\mathbf{0 . 8 2}$. Ajuste muy aceptable (Elaboración propia).

Validado el modelo MaxEnt y a partir del análisis de riesgos del sistema Xylella fastidiosa subsp. multiplex ST-6 y vector Philaneus spumarius, se estima que bajo las condiciones medioambientales propuestas y los datos de presencia de los brotes actualizados de la misma subespecie y ST, y de vectores positivos, se considera como muy probable (Riesgo>80 \%) la presencia de la bacteria y del vector en aquellas áreas en las que confluyan los siguientes parámetros:

Área 1. AUC: $91.5 \%$. Valores de ajuste para ambas especies considerado como bueno, error por comisión y omisión muy bajo según los criterios del manual técnico del software. (Merow et al. 2013). Testaje externo 914 puntos. Error de omisión $<20 \%$. Error de comisión $<10 \%$.

Alturas y orientaciones (MDT)

El óptimo altitudinal para Xylella fastidiosa subsp. multiplex ST-6 se encuentra en el rango de los 200 -600 metros, a partir de ella desciende la probabilidad hasta los 1000 metros de altitud (figura 11.b). Las orientaciones observadas según los estudios cartográficos manifiestan una predisposición a las laderas Sureste, Sur y Suroeste. El insecto vector (Philaenus spumarius) le hace ascender hasta los 700 metros, disminuyendo la probabilidad de presencia 
Romero Fernández, M. G. (2020): “Análisis de distribución potencial de Xylella fastidiosa subsp. multiplex ST-6 y Philaenus spumarius en el sur de la Península Ibérica mediante el modelo ecológico de nicho MaxEnt.", GeoFocus, $n^{\circ} 25$, p. 77-102. http://dx.doi.org/10.21138/GF.664

hacia los 1200 metros. Las orientaciones de los sistemas montañosos son homólogos a los que se encuentra la bacteria.

La altitud es un factor limitante para el emplazamiento de la bacteria y para el insecto vector. Es la segunda variable en el peso total de la probabilidad. Las sierras forman parte del Sistema Bético y se disponen paralelas, dirigidas de suroeste a noreste. Las altitudes máximas de los sistemas están en los 1400 metros. Las altitudes más bajas, zonas de valle y costera presentan una probabilidad más baja, pero esto puede ser debido a los usos del suelo en esta zona, ocupados por construcciones e infraestructuras que no permiten los cultivos propensos a padecer Xf.

Precipitación total anual (PREC)

Existe un óptimo de lluvia acumulada entre los 300 y $450 \mathrm{~mm} / \mathrm{año}$. En este sentido hay que tener presente que el rango superior está limitado por la propia precipitación media del área de estudio que no supera esta cantidad, por lo que técnicamente es imposible estimar probabilidad de presencia del patosistema en precipitaciones fuera de rango (Figura 12.a). El insecto presenta parámetros similares. Las zonas más sensibles corresponden a usos del suelo de cultivos frutales de secano, por lo que el factor hídrico es limitante tanto para la especie vegetal como para el sistema patógeno-vector. La humedad relativa juega un papel importante para las etapas de huevo y ninfas del vector por lo que es un factor limitante en épocas estivales, por lo que el aporte de humedad está relacionado con las precipitaciones estivales y vientos dominantes saturados procedentes del mar.

Temperatura media de las máximas (TMAX)

No existen suficientes datos al respecto en la bibliografía sobre la influencia de las temperaturas máximas en la introducción y establecimiento de la bacteria y del insecto. Por lo que respecta al estudio, existe un óptimo entre $\operatorname{los} 5^{\circ} \mathrm{C}$ y $\operatorname{los} 20^{\circ} \mathrm{C}$ de media (figura 12.c), produciéndose un descenso acusado a partir de $\operatorname{los} 25^{\circ} \mathrm{C}$, ratificando así lo expuesto por Purcell en condiciones de laboratorio y teniendo en cuenta que se tratan de temperaturas máximas absolutas (Feil y Purcell 2001). El insecto también presenta parámetros similares, ajustándose bastante bien a las temperaturas inferiores a $5{ }^{\circ} \mathrm{C}$ o superiores a $30^{\circ} \mathrm{C}$ que afectan negativamente a su supervivencia tal y como observa Saponari et al. (2014). Coincide con el momento de máximo desarrollo de las ninfas, más sensibles a las oscilaciones térmicas que los adultos. Las zonas de valle y desérticas con temperaturas máximas por encima de este máximo son también limitantes.

Temperatura media de las mínimas (TMIN)

Primera variable ponderada en el modelo, adecuándose a lo observado por Purcell sobre la influencia de la temperatura mínima en la aparición de $\mathrm{Xf}$, se ha comprobado que temperaturas medias mínimas por debajo de $5{ }^{\circ} \mathrm{C}$ afectan negativamente a la probabilidad de establecimiento de la bacteria, subiendo gradualmente la probabilidad de su ocurrencia a partir de los $6^{\circ} \mathrm{C}$. (Figura 12.d). Philaneus spumarius presenta también un mínimo por debajo de los $5{ }^{\circ} \mathrm{C}$ de media, aumentando su probabilidad por encima de $\operatorname{los} 8{ }^{\circ} \mathrm{C}$. Los datos indican que la mayoría de las muestras se han realizado durante los meses de abril y mayo en el estadio de ninfa, previo al paso de los cultivos afectados ya en estadio adulto. La temperatura mínima está estrechamente relacionada con la altitud por lo que puede ser una covariable de esta para explicar la dispersión del sistema patógeno-vector. 
Romero Fernández, M. G. (2020): “Análisis de distribución potencial de Xylella fastidiosa subsp. multiplex ST-6 y Philaenus spumarius en el sur de la Península Ibérica mediante el modelo ecológico de nicho MaxEnt.", GeoFocus, $n^{\circ} 25$, p. 77-102. http://dx.doi.org/10.21138/GF.664

Área 2. AUC: $99.7 \%$

Este área no tiene testaje externo ya que solo es una proyección de la potencialidad del riesgo de presencia del patosistema y no se ha constatado presencia de enfermedad (Salvo un caso en invernadero en El Ejido (Almería) en cultivo bajo plástico (https://geographyca.us.es/XYLELLAANDALUCIA/index.html\#9/36.7930/-2.8345) y que está perfectamente ubicado en las áreas de máxima probabilidad de riesgo.

Valores de ajuste para ambas especies considerado como excelente, error por omisión casi nulo según los criterios del manual técnico del software. (Martínez 2014). El análisis del modelo muestra unos parámetros ambientales similares a los del área de origen (A1), salvo que la precipitación es con diferencia la que presenta mayor peso en la modelización. Se ha de tener presente que los rangos que excedan los valores originales han de ser tomados con precaución al ser un área mayor en extensión y con una mayor amplitud de los valores de las variables biogeográficas estudiadas. Por ello el modelo no ha realizado extrapolación alguna tal y como se detalla en la metodología y parámetros del sistema.

Régimen Agroclimático (Papadakis 1952), ambas áreas se clasifican como Régimen térmico Mediterráneo Marítimo y subtropical. El régimen térmico:

- Subtropical semicálido $(\mathrm{Su})$.

- Subtropical cálido (SU).

- Marítimo cálido (Ma).

Índice de Evapotranspiración: 850

\section{Discusión y valoración}

El grado de certidumbre de los modelos de nicho ecológico que reflejan la probable distribución de una especie en el espacio geográfico, depende de múltiples factores como la naturaleza, complejidad y exactitud de los modelos usados, la calidad de las capas de datos ambientales disponibles, de los datos de la distribución de la especie y de la influencia de otros factores de nicho como barreras o perturbaciones para la dispersión, así como la existencia de otras especies que interactúan con la especie objeto en su biocenosis y que pueden impedir la ocupación actual de los hábitats potenciales identificados por el modelo, si no se tienen presentes en el estudio (Guissan y Thuiller 2005).

Esta cuestión se ha hecho patente en el caso que nos ocupa al ser la enfermedad una combinación de al menos dos especies conformando un sistema patógeno-vector. El estudio de este último si cabe, tiene una vital importancia como se ha manifestado por su alta correlación de su presencia con la de la bacteria en la modelización, por encima del $94 \%$ al ser el principal transmisor de la bacteria a cortas y medias distancias y por su movilidad.

Otra cuestión de gran importancia es la individualización de las cepas de Xf. El estudio de la distribución potencial de la bacteria presente en un territorio se debe basar en la determinación de la subespecie y ST o cepa. Los estudios derivados hasta la fecha sostienen que la pretendida introducción del fitopatógeno en la península no puede achacarse a las poblaciones de la bacteria causantes de la enfermedad en las especies vegetales de las Islas Baleares, al tratarse de subespecies y ST distintas (Blanca et al. 2017). Por tanto, los estudios realizados en distribuciones espaciales en los que se han utilizado muestreos no contrastados y sin tener 
Romero Fernández, M. G. (2020): “Análisis de distribución potencial de Xylella fastidiosa subsp. multiplex ST-6 y Philaenus spumarius en el sur de la Península Ibérica mediante el modelo ecológico de nicho MaxEnt.", GeoFocus, $n^{\circ} 25$, p. 77-102. http://dx.doi.org/10.21138/GF.664

presente la discriminación previa entre las distintas subespecies y ST, deberían ser estudiados y analizados con precaución. (Gutiérrez Hernández y García 2018, Gutiérrez Hernández y García 2019).

Para realizar estudios más rigurosos y desde el punto de vista de los muestreos que optimicen los recursos destinados para su seguimiento y control sobre distribuciones potenciales de la bacteria, es necesario alcanzar un mayor grado de especificidad y sobre todo, una mayor resolución espacial que permita una aproximación más ajustada a la gestión y manejo de fitopatógenos en ecosistemas agroforestales, como se ha analizado en este trabajo, alcanzando resoluciones espaciales de $30 \times 30 \mathrm{~m}^{2}$ (Bosso et al. 2016).

Algunos autores recomiendan trabajar con el más amplio conjunto de datos disponible sobre la especie invasora, tanto en el rango nativo de su distribución como en el área donde aparece como organismo invasor (Jiménez-Valverde et al. 2011). El problema es que no siempre están disponibles esos datos y en muchos casos las administraciones públicas no facilitan el acceso a los mismos, lo que dificulta el desarrollo de trabajo, como ha ocurrido con los datos de las Islas Baleares. En cuanto a esta última cuestión de los datos proporcionados y de su calidad, sobre los que se realiza el estudio, presentan una serie de dudas sobre cuál ha sido la técnica de muestreo empleada para cada uno de los diez brotes reconocidos en la provincia de Alicante, observándose un $15 \%$ de errores de posicionamiento con respecto a la parcela catastral de referencia.

La elección de este modelo se ha establecido por cuestiones prácticas y por ser el más utilizado en la modelización de especies de reciente introducción y especialmente para la enfermedad que nos ocupa (Gutiérrez Hernández y García 2018, Gutiérrez Hernández y García 2019, Bosso et al. 2016).

El modelo de distribución MaxEnt parece ser un software fiable para el estudio en cuestión por las cuestiones técnicas que requiere y por los resultados obtenidos. Existen grandes diferencias entre los distintos algoritmos en cuanto al coste computacional ya que es junto a Bioclim y Domain, uno de los más rápidos de ejecución, (Benito de Pando y Peñas de Giles 2007).

El modelo dispone de un estadístico robusto, al presentar el área debajo de curva (AUC) que mide la capacidad discriminante y otorgar una validez razonable al estudio, siendo sensible al tamaño y configuración del área (Elith et al. 2011), cuestión esta que se ha verificado al realizar la modelización para dos áreas de tamaño distinto, pero bajo los mismos parámetros y puntos de presencia, y la comprobación del error de comisión y omisión de manera externa al modelo. Esta validación externa ha sido una de las aportaciones más relevantes, ya que no se había realizado hasta el presente trabajo.

Aunque el modelo no trabaja con datos de "no presencia" de la especie, ya que mide el potencial biotopo acorde a unas condiciones medioambientales predefinidas y aceptando el error por comisión, se ha creído conveniente para validar el modelo, introducir estas no presencias como los negativos del muestreo sólo en la especie vegetal afectada por cantidad y extensión. (Prunus dulcis). Es habitual que en los muestreos de especies exóticas o amenazadas no se registren las ausencias, pero en este caso y dado la importancia de la enfermedad, las intensidades de los muestreos han permitido obtener estos datos y emplear técnicas más precisas, ya que en general los resultados apuntan a los métodos de presencia-ausencia como los de mayor precisión, por lo que se ha propuesto una metodología de modelización que tiene en cuenta estas ausencias para su validación. (Elith et al. 2011, Phillips et al. 2006).

La modelización sobre superficies de distinto tamaño ha reflejado la bondad que tiene el algoritmo al validar las áreas de más superficie, comprobando que las curvas AUC se ajustan 
Romero Fernández, M. G. (2020): “Análisis de distribución potencial de Xylella fastidiosa subsp. multiplex ST-6 y Philaenus spumarius en el sur de la Península Ibérica mediante el modelo ecológico de nicho MaxEnt.", GeoFocus, $n^{\circ} 25$, p. 77-102. http://dx.doi.org/10.21138/GF.664

casi perfectamente con más de un $95 \%$ para el área A2 descendiendo hasta el $90 \%$ en el área A1, más pequeña. Aun así, son valores muy altos de fiabilidad del modelo, tal y como se ha comentado en la parte técnica de MaxEnt. Normalmente, los modelos de especies ubicuas muestran valores de AUC más bajos que los de las especialistas o exigentes, por lo que es más fácil modelizar especies ligadas a entornos muy concretos (Moreno Amat 2017).

\section{Conclusiones}

Se ha comprobado el grado de validez del modelo con el estudio del error por comisión y omisión que facilita el propio modelo mediante las curvas ROC y el estadístico AUC, con ajuste excelentes por encima del $90 \%$ de verdaderos positivos predichos. También se ha realizado una validación externa del error de omisión al introducir la presencia de los muestreos del último brote como datos de prueba (914 puntos). Este error se ha estimado en menor del $20 \%$. El error de comisión se ha estimado en menos del $10 \%$ al comprobar que más del $90 \%$ de las muestras negativas de almendro de la ZD han sido correctamente identificada por MaxEnt como baja probabilidad de riesgo (verdaderos negativos).

La correlación del modelo matemático y la predicción cartográfica de MaxEnt ha presentado un buen ajuste $(\mathrm{R}>80 \%)$. Se han introducido para ambos casos los 914 puntos de validación, asignando valores del mapa de riesgo calculado de Xf y el riesgo potencial calculado por la ecuación matemática mediante el ajuste a un modelo de regresión lineal múltiple potencial de las variables biogeográficas correspondientes para esos puntos.

Las variables ambientales seleccionadas han permitido delimitar bajo criterios del régimen agroclimático de Papadakis un clima de régimen térmico Mediterráneo Marítimo y Subtropical, climas mediterráneos costeros y del interior, pero de cierta altitud, que suavicen las temperaturas extremas del mes cálido. Siguiendo criterios biogeográficos estudiados, las zonas de alta montaña que superen los 1.000 metros de altitud en orientaciones Norte y de alturas por encima de 1.500 metros en orientaciones Sureste, Suroeste pueden tener las condiciones desfavorables para su introducción y por lo tanto actuar como barreras biogeográficas a la dispersión del patosistema.

La ponderación que establece MaxEnt para las variables estudiadas otorga a la precipitación con lluvia acumulada en torno a los 500-600 mm/año, el mayor peso en la probabilidad de presencia en el área A2, aun cuando hay que tener presente el rango de esta variable utilizada en la modelización del área A1, menor al del área A2. En el área A1 la variable de la temperatura media mínima tiene un mayor peso en el algoritmo, tanto esta como la temperatura media máxima presentan una ponderación elevada en el área A2.

La temperatura media máxima ha sido si cabe más importante ya que discrimina la presencia del patosistema en áreas geográficas con regímenes mediterráneos más extremos actuando como limites o perturbaciones en la probabilidad de presencia del patosistema. El límite inferior para el establecimiento del patosistema y siguiendo un criterio bioclimático, lo marcarían los climas mediterráneos infra y termomediterráneos (Desierto almeriense y valle del Guadalquivir) y el límite superior lo marcarían climas Supramediterráneos y de alta montaña como ya se ha mencionado.

Se ha podido validar externamente con los datos de prueba, la ponderación de cada variable biogeográfica implementada en el modelo y comprobar el ajuste de cada curva y los óptimos dentro de sus rangos. (figura 12)

La complejidad del patosistema requiere de estudios más precisos en cuanto a la resolución espacial y temporal, que permitan la optimización de áreas más propicias para 
Romero Fernández, M. G. (2020): “Análisis de distribución potencial de Xylella fastidiosa subsp. multiplex ST-6 y Philaenus spumarius en el sur de la Península Ibérica mediante el modelo ecológico de nicho MaxEnt.", GeoFocus, $n^{\circ} 25$, p. 77-102. http://dx.doi.org/10.21138/GF.664

realizar un mayor esfuerzo de muestreo de bacteria e insecto vector, mediante imágenes multi e hiperespectrales combinadas con datos LIDAR y dirigidas a las áreas clasificadas con alta probabilidad de presencia por modelos de nicho ecológico como MaxEnt. Se ha comprobado como la malla de muestreo propuesta por la administración, al carecer de estudios de riesgo como el propuesto puede estar cometiendo errores de omisión graves.

Objetivos posteriores se encaminarán a implementar técnicas y procedimiento que permitan alcanzar niveles de individualización de especies vegetales y su seguimiento fitopatológico mediante la correlación de las variables físicas con las ecológicas. También se pretende implementar un sistema de Información Geográfica mediante un servidor Geoserver (Centos 7) con toda la información y estudios recabados procedentes del visor ya en uso por el equipo de investigación. https://geographyca.us.es/Xylella.html

\section{Agradecimientos}

Al Dr. D. Fernando Díaz del Olmo, director de mi tesis doctoral de la que el presente artículo es el fruto del periodo de investigación. Al Dr. D. Rafael Cámara Artigas director del equipo de investigación al que pertenezco, y al Dr. D. Salomón Montesinos Aranda, por su inestimable ayuda.

\section{Referencias bibliográficas}

Aguayo, J., Elegbede, F., Husson, C., Saintonge, F., Marcais, B. (2014): "Modeling climate impact on an emerging disease, the Phytophthora alninduced alder decline", Global Change Biology, 20, 10, 3.209-3.221. https://doi.org/10.1111/gcb.12601.

Almeida, R. P., Nunney, L. (2015): "How do plant diseases caused by Xylella fastidiosa emerge?", Plant Dis, 99, 11, 1457-1467. https://doi.org/10.1094/PDIS-02-15-0159-FE

Anas, O., Harrison, U. J., Brannen, P. M., Sutton, T. B. (2008): “The Effect of Warming Winter Temperatures on the Severity of Pierce's Disease in the Appalachian Mountains and Piedmont of the Southeastern United States", Plant Health Progress, 9, 1, 13. https://doi.org/10.1094/PHP2008-0718-01-RS

Baskerville, G. L. (1972): "Regression in the estimation of plant biomass", Canadian Journal of Forestry, 2, 49-53. https://doi.org/Export Date 18 February 2014

Benito de Pando, B., Peñas de Giles, J. (2007): "Aplicación de modelos de distribución de especies a la conservación de la biodiversidad en el sureste de la Península Ibérica", GeoFocus 7, 100-119. https://www.researchgate.net/publication/28186522

Benito de Pando, B. (2015): XI Taller GBIF sobre Modelización de Nichos Ecológicos, organizado por GBIF.ES. Real Jardín Botánico-CSIC, Madrid. https://youtu.be/9xzFLoza5fw (consultado 03-03-2020)

Blackmer, J., Hagler, J. R., Simmons, G. S., Cañas, L. A. (2004): "Comparative Dispersal of Homalodisca coagulata and Homalodisca liturata (Homoptera: Cicadellidae)", Environmental Entomology, 33, 1, 88-99. https://doi.org/10.1603/0046-225X-33.1.88

Bosco, D., Cornara, D., Fereres. A. (2018): "Philaenus spumarius: when an old acquaintance becomes a new threat to European agriculture", Journal of Pest Science, 91, 3, 957-972 https://doi.org/10.1007/s10340-018-0966-0 
Romero Fernández, M. G. (2020): “Análisis de distribución potencial de Xylella fastidiosa subsp. multiplex ST-6 y Philaenus spumarius en el sur de la Península Ibérica mediante el modelo ecológico de nicho MaxEnt.", GeoFocus, $n^{o}$ 25, p. 77-102. http://dx.doi.org/10.21138/GF.664

Bosso, L., Russo, D., Di Febbraro, M., Cristinzio, G., Zoina, A. (2016): "Potential distribution of Xylella fastidiosa in Italy: A maximum entropy model", Phytopathologia Mediterranea, 55, 1, 62-72. https://doi.org/10.14601/Phytopathol_Mediterr-16429

Busby, J. R. (1991): “BIOCLIM a bioclimate analysis and prediction system”, Plant Protection Quarterly, 6, 1, 8-9.

Conselleria de Medi Ambient, (2017): Detecció nous brots XF.pdf. Palma de Mallorca Govern Illes

Balears. https://www.caib.es/sites/sanitatvegetal/es/brotes/archivopub.do?ctrl=MCRST94ZI221178\&id= $\underline{221178}$ (consultado 03-03-2018).

Consejo europeo (2000): Directiva 2000/29/CE del Consejo de 8 de mayo de 2000 relativa a las medidas de protección contra la introducción en la Comunidad de organismos nocivos para los vegetales o productos vegetales y contra su propagación en el interior de la Comunidad. https://eur-

lex.europa.eu/LexUriServ/LexUriServ.do?uri=CONSLEG:2000L0029:20090303:ES:PDF (consultado 03-03-2018).

Conselleria d'Agricultura, Medi Ambient, Canvi Climàtic i Desenvolupament Rural Conselleria de Agricultura, Medio Ambiente, Cambio Climático y Desarrollo Rural. (2018). Declaración de presencia de Xf. Valencia. http://www.dogv.gva.es/datos/2018/11/12/pdf/2018 10400.pdf (consultado 23-09-2018).

Conselleria d'Agricultura, Medi Ambient, Canvi Climàtic i Desenvolupament Rural Conselleria de Agricultura, Medio Ambiente, Cambio Climático y Desarrollo Rural. (2017a). Declaración de presencia de Xf. Valencia. http://www.dogv.gva.es/datos/2017/07/07/pdf/2017_6203.pdf (consultado 03-03-2018).

Conselleria d'Agricultura, Medi Ambient, Canvi Climàtic i Desenvolupament Rural Conselleria de Agricultura, Medio Ambiente, Cambio Climático y Desarrollo Rural. (2017b). Declaración de presencia de Xf. Valencia. http://www.dogv.gva.es/datos/2017/10/24/pdf/2017 9390.pdf (consultado 03-10-2017).

Merow, C., Smith, M.J., Silander, J.A. (2013): "A practical guide to MaxEnt for modeling species' distributions: what it does, and why inputs and settings matter", Ecography, 36, 10581069. doi: 10.1111/j.1600-0587.2013.07872.x

Coviella, C., Garcia, J. F., Jeske, D. R., Redak, R. A., Luck, R. F. (2006): "Feasibility of Tracking Within-Field Movements of Homalodisca coagulata (Hemiptera: Cicadellidae) and Estimating Its Densities Using Fluorescent Dusts in Mark-Release-Recapture Experiments", Journal of Economic Entomology, 99, 4, 1.0511.057. https://doi.org/10.1093/jee/99.4.1051

Cruz-Cárdenas, G., Villaseñor, J. L., López-Mata, L., Martínez-Meyer, E., Ortiz, E. (2014): "Selección de predictores ambientales para el modelado de la distribución de especies en MaxEnt", Revista Chapingo, Serie Ciencias Forestales y Del Ambiente, 20, 2, 187-201. https://doi.org/10.5154/r.rchscfa.2013.09.034

Der, G., Everitt, B. S. (2002): A handbook of statistical analyses using SAS. Chapman and Hall/CRC, Boca Ratón.

Dirección General de Sanidad de la Producción Agraria-MAPAMA. (2019): "Programa nacional para la aplicación de la normativa fitosanitaria". https://www.mapa.gob.es/es/agricultura/temas/sanidad- 
Romero Fernández, M. G. (2020): “Análisis de distribución potencial de Xylella fastidiosa subsp. multiplex ST-6 y Philaenus spumarius en el sur de la Península Ibérica mediante el modelo ecológico de nicho MaxEnt.", GeoFocus, $n^{\circ} 25$, p. 77-102. http://dx.doi.org/10.21138/GF.664

vegetal/xylella fastidiosa contingencia julio 2019 tcm30-512206.pdf (consultado 02-032018).

Drosopoulos, S., Remane, R. (2000): "Biogeographic studies on the spittlebug Philaenus signatus Melichar, 1896 species group (Hemiptera: Aphrophoridae) with the description of two new allopatric species", Annales de La Société entomologique de France, 36, 3, 269-277. http://gallica.bnf.fr/ark:/12148/bpt6k6142003d/f51

Elith, J., Phillips, S. J., Hastie, T., Dudík, M., Chee, Y. E., Yates, C. J. (2011): “A statistical explanation of MaxEnt for ecologists", Diversity and Distributions, 17, 1, 43-57. https://doi.org/10.1111/j.1472-4642.2010.00725.x

European Food Safety Authority (EFSA). (2015): "Scientific Opinion on the risks to plant health posed by Xylella fastidiosa in the EU territory, with the identification and evaluation of risk reduction options", EFSA Journal, 13, 1, 3989. https://doi.org/10.2903/j.efsa.2015.3989

Fabre, A., Carballo, C., Hernández, E., Piriz, P., Bergamino, L., Mello, L., González, S., Pérez, G., León, J., Aubriot, L., Bonilla, S., Kruk, C. (2010): "El nitrógeno y la relación zona eufótica/zona de mezcla explican la presencia de cianobacterias en pequeños lagos subtropicales, artificiales de Uruguay", Pan-American Journal of Aquatic Sciences, 5, 1, 112 125 .

Feil, H., Purcell, A. H. (2001): "Temperature-Dependent Growth and Survival of Xylella fastidiosa in Vitro and in Potted Grapevines", Plant Dis, 85, 1.230-1.234. https://apsjournals.apsnet.org/doi/pdf/10.1094/PDIS.2001.85.12.1230

Generalitat Valenciana, Consejería de Agricultura, Medio Ambiente, (2019): Plan de Acción frente a Xylella fastidiosa en la Comunidad Valenciana. http://www.agroambient.gva.es/documents/163214705/163847802/Plan+de+Accion+GVA+Xyl ella++fastidiosa_marzo+2019_firmado.pdf/f3064e0d-8ea1-46b0-8f9b-5ebeba683186 (consultado 21-04-2019).

Godefroid, M., Cruaud, A., Streito, J. C., Rasplus, J. Y., Rossi, J. P. (2018): "Climate change and the potential distribution of Xylella fastidiosa in Europe", bioRxiv. https://doi.org/10.1101/289876

Guisan, A., Thuiller, W. (2005): "Predicting species distribution: offering more than simple habitat models", Ecology Letters, 8, 9, 993-1.009. http://doi.wiley.com/10.1111/j.14610248.2005.00792.x

Gutiérrez Hernández, O., García, L. V. (2018): "Incidencia de Xylella fastidiosa en las Islas Baleares y distribución potencial en la península ibérica", Investigaciones Geográficas, 69, 5572. https://doi.org/10.14198/INGEO2018.69.04

Gutiérrez Hernández, O., García, L. V. (2019): "La dimensión geográfica de las invasiones biológicas en el Antropoceno: el caso de Xylella fastidiosa", Boletín de la Asociación de Geógrafos Españoles, 80, 2.771, 1-32. http://dx.doi.org/10.21138/bage.2771

Hijmans, R. J., Cameron, S. E., Parra, J. L., Jones, P. G., Jarvis, A. (2005): "Very high resolution interpolated climate surfaces for global land areas", International Journal of Climatology, 25, 15, 1.965-1.978. https://doi.org/10.1002/joc.1276

Hirzel, A. H., Hausser, J., Chessel, D., Perrin, N. (2002): "Ecological-niche factor analysis: How to compute habitat- suitability maps without absence data?", Ecology, 83, 2.027-2.036. https://doi.org/10.1890/0012-9658(2002)083[2027:ENFAHT]2.0.CO;2

Hoddle, M. S. (2004): "The potential adventive geographic range of glassy-winged 
Romero Fernández, M. G. (2020): “Análisis de distribución potencial de Xylella fastidiosa subsp. multiplex ST-6 y Philaenus spumarius en el sur de la Península Ibérica mediante el modelo ecológico de nicho MaxEnt.", GeoFocus, $n^{\circ} 25$, p. 77-102. http://dx.doi.org/10.21138/GF.664

sharpshooter, Homalodisca coagulata and the grape pathogen Xylella fastidiosa: implications for California and other grape growing regions of the world", Crop Protection, 23, 691-699. https://doi.org/10.1016/j.cropro.2003.11.017

Janse, J. D., Obradovic, A. (2010): "Xylella fastidiosa: Its biology, diagnosis, control and risks", $\begin{array}{lllll}\text { Journal of } & \text { PlantPathology, } & 92, & 1,\end{array}$ http://www.sipav.org/main/jpp/index.php/jpp/article/view/2504

Jaynes, E. T. (1957): "Information theory and statistical mechanics", Phys. Rev, 106, 620-630. https://doi.org/10.1103/PhysRev.106.620

Jiménez-Valverde, A., Peterson, A., Soberon, T., Overton, J. M., Aragón, P., Lobo, J. M. (2011): "Use of niche models in invasive species risk assessments", Biol Invasions, 13, 2.7852.797. https://doi.org/10.1007/s10530-011-9963-4

Krell, R. K., Boyd, E. A., Nay, J. E., Park, Y. L., Perring, T. M. (2007): "Mechanical and insect transmission of Xylella fastidiosa to Vitis vinifera", American Journal of Enology and Viticulture, 58, 2, 211-216. https://pubag.nal.usda.gov/catalog/2805567

Krugner, R., Ledbetter, C.A. (2016): "Rootstock Effects on Almond Leaf Scorch Disease Incidence and Severity", Plant Disease, 85, 1.230-1.234. https://doi.org/10.1094/PDIS-01-16$\underline{0125-\mathrm{RE}}$

Kumar, S., Stohlgren, T. J. (2009): "MaxEnt modeling for predicting suitable habitat for threatened and endangered tree Canacomyrica monticola in New Caledonia", Journal of Ecology and Natural Environment, 1, 4, 94-98.

Landa, L., Marco-Noales, E., López, M. M. (2017): Enfermedades causadas por la bacteria Xylella fastidiosa.

Cajamar.

https://www.publicacionescajamar.es/publicacionescajamar/public/pdf/seriestematicas/informes-coyuntura-monografias//enfermedades-causadas-por-la-bacteria-2.pdf (consultado 07-09-2018).

Martelli, G. P. (2016): "The current status of the quick decline syndrome of olive in southern Italy", Phytoparasitica, 44, 1, 1-10. https://doi.org/10.1007/s12600-015-0498-6

Martínez, N. (2014): Apuntes sobre Modelización de Nicho Ecológico. http://www.mncn.csic.es/docs/repositorio/es_ES/Blog/Documentos_blog/apuntes-sigmodelacion.pdf (consultado 11-04-2018).

Moreno Amat, E. (2017): "Reducción de la incertidumbre de los modelos de distribución de especies con datos ecológicos y paleoecológicos", Ecosistemas, 26, 3, 106-109. https://doi.org/10.7818/ECOS.2017.26-3.13

Paião, F. G., Meneguim, A. M., Casagrande, E. C., Leite, R. P. (2002): "Envolvimento de cigarras (Homoptera, Cicadidae) na transmissão de Xylella fastidiosa em cafeeiro", Fitopatol Bras, 27-67. http://www.sbicafe.ufv.br/handle/123456789/1457

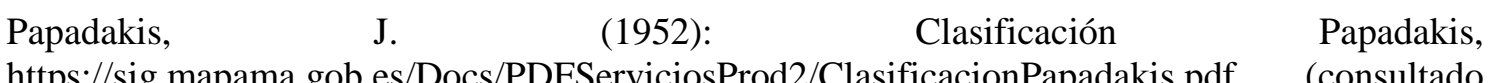
11-04-2018).

Peterson, A. T. et al. (2012): Ecological niches and geographic distributions, Princeton, Princeton University Press. https://doi.org/10.5860/CHOICE.49-6266

Plantegenest, M., Le May, C., Fabre, F. (2007): "Landscape epidemiology of plant diseases", Journal of the Royal Society Interface, 4, 16, 963-972. https://doi.org/10.1098/rsif.2007.1114 
Romero Fernández, M. G. (2020): “Análisis de distribución potencial de Xylella fastidiosa subsp. multiplex ST-6 y Philaenus spumarius en el sur de la Península Ibérica mediante el modelo ecológico de nicho MaxEnt.", GeoFocus, $n^{\circ} 25$, p. 77-102. http://dx.doi.org/10.21138/GF.664

Phillips, S. J., Dudi, M. (2008). "Modeling of species distributions with MaxEnt: new extensions and a comprehensive evaluation", Ecography, 31, 161-175. https://doi.org/10.1111/j.0906-7590.2008.5203.x

Phillips, S. J., Anderson, R., Schapire, R. E. (2006): "Maximum entropy modeling of species geographic distributions", Ecological Modelling, 190, 3, 231-259. https://doi.org/10.1016/j.ecolmodel.2005.03.026

Purcell, A. H. (1989): "Homopteran transmission of Xylella fastidiosa, inhabiting bacteria", Advances in desease vector research, 6, 243-266. https://doi.org/10.1007/978-1-4612-32926_9

Purcell, A. H. (1997): “Xylella fastidiosa, a regional problem or global threat?", Journal of Plant Pathology, 79, 99-105. https://www.jstor.org/stable/41997874

Purcell, A. H., Almeida, R. (2003): "Transmission of Xylella fastidiosa to grapevines by Homalodisca coagulata (Hemiptera, Cicadellidae)", Journal of Economic Entomology, 96, 265271. https://nature.berkeley.edu/almeidalab/wp-content/uploads/2015/11/Almeida03.pdf

Saponari, M., Loconsole, G., Cornara, D., Yokomi, R. K., De Stradis, A., Boscia, D., Porcelli, F. (2014): "Infectivity and Transmission of Xylella fastidiosa by Philaenus spumarius (Hemiptera: Aphrophoridae) in Apulia, Italy", Journal of Economic Entomology, 107, 4, 13161319. https://doi.org/10.1603/EC14142

Stewart, A. J. A., Lees, D. R. (1988): "Genetic control of colour/pattern polymorphism in British populations of the spittlebug Philaenus spumarius (L.) (Homoptera: Aphrophoridae)", Biological Journal of the Linnean Society, 34, 57-79. http://dx.doi.org/10.1111/j.1095$\underline{\text { 8312.1988.tb01948.x }}$

Sutherst. R. W., Maywald. G., Kriticos, D.J. (2007): "CLIMEX version 3: user's guide", Melbourne. Hsubsp editor. http://hdl.handle.net/102.100.100/127529?index=1

Weawer, C., King, D. (1954): Meadow spittlebug, Philaenus leucophthalmus (L.). Ohio, Ohio Agricultural Experiment Station. http://hdl.handle.net/1811/63036 (consultado 22-10-2018).

Wells, J., Raju, B., Hung, H. Y., Weisburg, W., Mandelco-Paul, L., Brenner, D. (1987): "Xylella fastidiosa gen. nov, sp. nov: gram-negative, xylem-limited, fastidious plant bacteria related to Xanthomonas campestris", International Journal of Systematic and Evolutionary Microbiology, 37, 2, 136-143. https://doi.org/10.1099/00207713-37-2-136

Winkler, A. J. (1949): "Pierce's Diseases Invetigations", H I L G A R D I A Journal of Agricultural Science Published by the California Agricultural Experiment Station, 19, 7, 207264. http://hilgardia.ucanr.edu/fileaccess.cfm?article=152313\&p=CHPMRE

Wisz, M. S., Hijmans, R. J., Li, J., Peterson, A. T., Graham, C. H., Guisan, A. (2008): "Effects of sample size on the performance of species distribution models", Diversity and Distributions, 14, 5, 763-773. https://doi.org/10.1111/j.1472-4642.2008.00482.x

Wood, A. G. (1986): Statistics and data handling A potential bias in log-transformed allometric equations. $\quad$ https://sora.unm.edu/sites/default/files/journals/iws/n006/p00137-p00138.pdf (consultado 05-12-2018). 